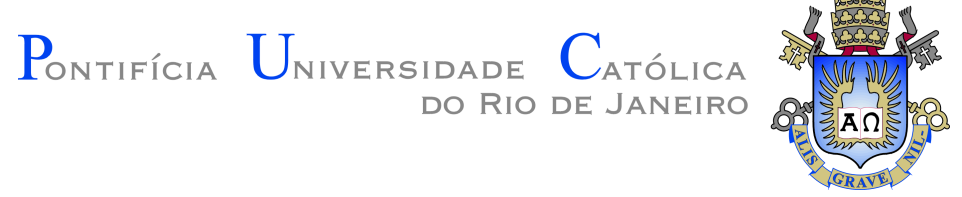

Alice Herrera de Figueiredo

Campos de direcionalidade na geração e avaliação de malhas de quadriláteros

Dissertação de Mestrado

Dissertação apresentada como requisito parcial para a obtenção do grau de Mestre pelo Programa de Pós-graduação em Informática da PUC-Rio.

Orientador: Prof. Waldemar Celes Filho 


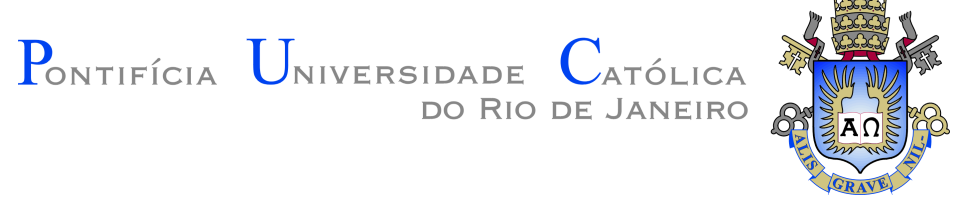

Alice Herrera de Figueiredo

\title{
Campos de direcionalidade na geração e avaliação de malhas de quadriláteros
}

Dissertação apresentada como requisito parcial para a obtenção do grau de Mestre pelo Programa de Pós-graduação em Informática da PUC-Rio. Aprovada pela Comissão Examinadora abaixo assinada.

\author{
Prof. Waldemar Celes Filho \\ Orientador \\ Departamento de Informática - PUC-Rio \\ Prof. Emilio Ashton Vital Brazil \\ IBM Research Brazil \\ Prof. Sinesio Pesco \\ Departamento de Matemática - PUC-Rio \\ Prof. Marcelo Gattass \\ Departamento de Informática - PUC-Rio
}

Prof. Luiz Fernando Campos Ramos Martha

Departamento de Engenharia Civil - PUC-Rio

Prof. Márcio da Silveira Carvalho

Coordenador Setorial do Centro Técnico Científico - PUC-Rio 
Todos os direitos reservados. É proibida a reprodução total ou parcial do trabalho sem autorização da universidade, do autor e do orientador.

\section{Alice Herrera de Figueiredo}

Graduou-se em Engenharia da Computação pela Pontifícia Universidade Católica do Rio de Janeiro (PUC-Rio), onde trabalhou em projetos no grupo de visualização do Instituto Tecgraf. Em 2015 ingressou no programa de mestrado em Informática na Pontifícia Universidade Católica do Rio de Janeiro (PUC-Rio). Durante o mestrado, continuou seu trabalho e sua pesquisa no grupo de visualização do Instituto Tecgraf.

Ficha Catalográfica

Herrera de Figueiredo, Alice

Campos de direcionalidade na geração e avaliação de malhas de quadriláteros / Alice Herrera de Figueiredo; orientador: Waldemar Celes Filho. - Rio de Janeiro: PUC-Rio, Departamento de Informática, 2017.

v., 59 f: il. color. ; $30 \mathrm{~cm}$

Dissertação (mestrado) - Pontifícia Universidade Católica do Rio de Janeiro, Departamento de Informática.

Inclui bibliografia

1. Informática - Teses. 2. Partição de Domínio;. 3. Malha; 4. Quadrilátero.. I. Celes Filho, Waldemar. II. Pontifícia Universidade Católica do Rio de Janeiro. Departamento de Informática. III. Título. 


\section{Agradecimentos}

Ao meu orientador Waldemar, pela paciência e confiança desde a graduação.

Aos meus amigos e colegas do Tecgraf. Em especial, a Vinícius, Chrystiano, Rodrigo, Netto, Vicente e Rustam, por toda a ajuda e atenção sempre.

À minha família Herrera e Figueiredo, por todo o amor e carinho nesses 26 anos.

A todos meus queridos amigos, que me energizam diariamente.

Ao Ricardo, por todo apoio e crescimento nos últimos meses e toda amizade nos útimos sete anos.

À minha irmã, Silvia, por ser meu porto seguro.

Aos meus pais, Celina e Luiz, por estarem ao meu lado todos os dias. Por serem minha inspiração e meu maior orgulho.

À Capes, ao Tecgraf e à PUC-Rio pelos auxílios concedidos, que possibilitaram a realização deste trabalho. 


\section{Resumo}

Herrera de Figueiredo, Alice; Celes Filho, Waldemar. Campos de direcionalidade na geração e avaliação de malhas de quadriláteros. Rio de Janeiro, 2017. 59p. Dissertação de Mestrado - Departamento de Informática, Pontifícia Universidade Católica do Rio de Janeiro.

Um dos principais desafios para a geração de malhas de quadriláteros é garantir o alinhamento dos elementos em relação às restrições do domínio. Malhas não alinhadas introduzem problemas numéricos em simulações que usam essas malhas como subdivisão do domínio. No entanto, não existe uma métrica de alinhamento para a avaliação de qualidade de malhas de quadriláteros. Um campo de direcionalidade representa a difusão das orientações das restrições no interior do domínio. Kowalski et al. usam um campo de direcionalidade para particionar o domínio em regiões quadrilaterais. Neste trabalho, reproduzimos o método de particionamento proposto por Kowalski et al. com algumas alterações, visando reduzir o número final de partições. Em seguida, propomos uma métrica para avaliar a qualidade de malhas de quadriláteros em relação ao alinhamento com as restrições do domínio.

\section{Palavras-chave}

Partição de Domínio; Malha; Quadrilátero. 


\section{Abstract}

Herrera de Figueiredo, Alice; Celes Filho, Waldemar (Advisor). Directionality fields in generation and evaluation of quadrilateral meshes. Rio de Janeiro, 2017. 59p. Dissertação de Mestrado

- Departamento de Informática, Pontifícia Universidade Católica do Rio de Janeiro.

One of the main challenges in quadrilateral mesh generation is to ensure the alignment of the elements with respect to domain constraints. Unaligned meshes insert numerical problems in simulations that use these meshes as a domain discretization. However, there is no alignment metric for evaluating the quality of quadrilateral meshes. A directionality field represents the diffusion of the constraints orientation to the interior of the domain. Kowalski et al. use a directionality field for domain partitioning into quadrilateral regions. In this work, we reproduce their partitioning method with some modifications, aiming to reduce the final number of partitions. We also propose a metric to evaluate the quality of a quadrilateral mesh with respect to the alignment with domain constraints.

\section{Keywords}

Domain Partitioning; Mesh; Quadrilateral. 


\section{Sumário}

1 Introdução 11

2 Trabalhos relacionados $\quad 13$

2.1 Geração de malhas de quadriláteros $\quad 13$

$\begin{array}{ll}2.2 \text { Métricas de qualidade de malhas de quadriláteros } & 14\end{array}$

3 Partição do domínio em regiões quadrilaterais 17

$\begin{array}{lll}3.1 & \text { Campo de direcionalidade } & 18\end{array}$

3.2 Singularidades 20

$\begin{array}{ll}3.3 \text { Separatrizes } & 21\end{array}$

3.3.1 Combinação de separatrizes 23

3.3.2 Raio de influência 24

3.4 Geração da malha de quadriláteros 25

3.5 Implementação e Resultados 25

3.5.1 Campo de direcionalidade 26

$\begin{array}{ll}3.5 .2 & \text { Singularidades }\end{array}$

$\begin{array}{lll}3.5 .3 & \text { Separatrizes } & 31\end{array}$

3.5.4 Variação do raio de influência 34

3.5.5 Partição de domínios com restrições 34

$4 \quad$ Métrica de qualidade de alinhamento de malhas quadrilaterais 38

4.1 Exemplos 42

4.1.1 Influência do raio na qualidade da malha 42

4.1.2 Domínios com restrições 48

5 Conclusão $\quad 56$

$\begin{array}{ll}\text { Referências Bibliográficas } & 57\end{array}$ 


\section{Lista de figuras}

1.1 Exemplo de decomposição do domínio em regiões quadrilaterais e geração da malha de quadriláteros (9).

3.1 As etapas do método de Kowalski et al. (9).

3.2 Campo do vetor tangente é descontínuo em segmentos perpendiculares na fronteira do domínio.

3.3 A direcionalidade é contínua em segmentos perpendiculares na fronteira do domínio. $O$ vetor $\vec{v}_{0}$ está destacado em vermelho.

3.4 O vetor de representação é contínuo em segmentos perpendiculares na fronteira do domínio.

3.5 Exemplos de direcionalidade e seus vetores de representação (9). 20

3.6 Se a singularidade está em uma aresta, são considerados os dois triângulos que a contém.

3.7 Interseção das separatrizes de $S_{0}$ com o triângulo que ela pertence (9). 22

3.8 Processo de integração nos triângulos para definir as separatrizes (9). 22

3.9 Resultado da partição de um domínio em regiões quadrilaterais. Vemos suas as restrições em vermelho e em azul as separatrizes ao final da integração.

3.10 Caso em que uma singularidade encontra um raio de influência (11). 24

3.11 Região triangular (9).

3.12 Malha de quadriláteros gerada pelo método de Kowalski et al. (9). 25

3.13 Modelo com restrições tanto na fronteira quanto no interior. 26

3.14 Campos do eixo $x$ e do eixo $y$ dos vetores de representação. $\quad 27$

3.15 Campo do vetor de representação e da direcionalidade. 28

3.16 Utilizamos as coordenadas baricêntricas para encontrar os pontos de singularidade num triângulo.

3.17 A magnitude nula (azul) está relacionada com a região de singularidade. 30

3.18 A magnitude nula (azul) está diretamente relacionada com a região de singularidade.

3.19 Utilizamos os dois triângulos que compartilham a aresta mais próxima da singularidade para calcular o início das separatrizes referentes à essa singularidade.

3.20 Exemplo de singularidade geométrica e suas separatrizes. 33

3.21 Comparação entre diferentes raios no mesmo domínio. 35

3.22 Comparação entre diferentes raios no mesmo domínio. 35

3.23 Domínio com restrição em seu interior e a subdivisão gerada. 36

3.24 Malha de quadriláteros gerada a partir das regiões da Figura 3.23. 36

3.25 Domínio geológico. 37

4.1 Etapas da geração da métrica de qualidade de alinhamento de malhas quadrilaterais. 
4.2 Representação do desvio. As arestas da malha de quadriláteros estão representadas em cinza e a direcionalidade em preto. Os vetores azuis e vermelhos são os que usamos para calcular o ângulo entre uma aresta (azul) e o vetor da direcionalidade (vermelho) do vértice mais próximo dessa aresta.

4.3 Magnitude $(\alpha)$ do campo do vetor de representação da direcionalidade. 40

4.4 Métrica de qualidade de alinhamento, em o desvio $(d)$ representa a cor de cada vértice e a confiabilidade $(\alpha)$ a transparência da cor. $\quad 40$

4.5 Gráfico do desvio quantizado em intervalos de $\alpha$.

4.6 Gráfico de barras condensado, onde a altura de cada barra é ponderada pelo $\alpha$.

4.7 Modelos 1 e 2.

4.8 Magnitude do campo do vetor de representação da direcionalidade. 44

4.9 Métrica de qualidade de alinhamento. 45

4.10 Gráfico do desvio quantizado em intervalos de $\alpha$. 46

4.11 Gráfico de barras condensado. $\quad 47$

4.12 Modelo 3.

4.13 Magnitude do campo do vetor de representação da direcionalidade do Modelo 3.

4.14 Métrica de qualidade de alinhamento para o Modelo 3.

4.15 Gráfico do desvio quantizado em intervalos de $\alpha$. 49

4.16 Gráfico de barras condensado. $\quad 50$

4.17 Modelo 4 com suas restrições em vermelho. $\quad 51$

4.18 Magnitude do campo do vetor de representação da direcionalidade do Modelo 4.

4.19 Métrica de qualidade de alinhamento para o Modelo 4. 51

4.20 Gráfico do desvio quantizado em intervalos de $\alpha$. 52

4.21 Gráfico de barras condensado. 52

4.22 Área destacada do Modelo 4 para mostrar o desalinhamento. $\quad 53$

4.23 Modelo 5 com suas restrições em vermelho. 54

4.24 Magnitude do campo do vetor de representação da direcionalidade do Modelo 5.

4.25 Métrica de qualidade de alinhamento para o Modelo 5.

4.26 Gráfico do desvio quantizado em intervalos de $\alpha$.

4.27 Gráfico de barras condensado. 


\section{Lista de tabelas}

2.1 Métricas de qualidade para malhas de quadriláteros (2). 


\section{Introdução}

A discretização de domínios em malhas é uma tarefa central nas simulações numéricas em engenharia baseadas no método dos elementos finitos para a solução de sistemas de equações diferenciais parciais. Elementos quadrilaterais e hexaedrais são preferidos por terem melhores funções de interpolação. Quando comparados com triângulos, elementos quadrilaterais tendem a ser mais estáveis e precisar de menos refinamento (12). Além disso, a conversão de quadriláteros em triângulos é mais fácil do que ao contrário.

Neste trabalho, focamos na geração de malhas de quadriláteros utilizando como base o trabalho de Kowalski et al. (9), que apresenta um método para particionar o domínio em regiões quadrilaterais utilizando o conceito de direcionalidade. A partir de uma malha de triângulos, o método gera um campo de direcionalidade, através da resolução de uma equação diferencial parcial. Em seguida, utiliza as informações do campo de direcionalidade para achar os pontos de singularidade do campo e gerar separatrizes. As separatrizes são as linhas de fluxo que irão particionar o domínio em regiões quadrilaterais. Como essas regiões respeitam o campo de direcionalidade, qualquer método de mapeamento direto gera uma boa malha de quadriláteros, como ilustra a Figura 1.1.
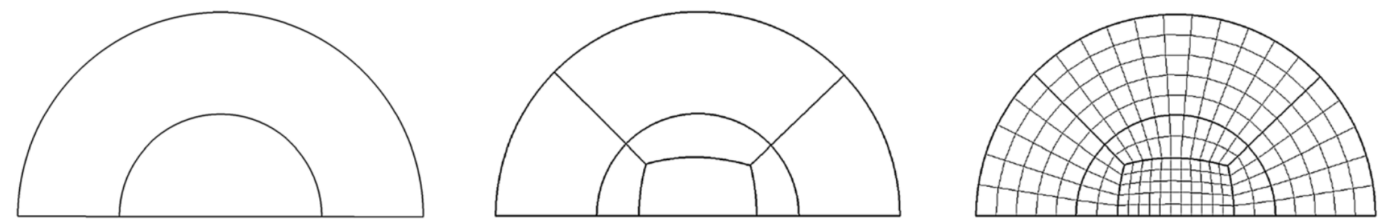

Figura 1.1: Exemplo de decomposição do domínio em regiões quadrilaterais e geração da malha de quadriláteros (9).

As principais contribuições desta dissertação são:

- Revisitação do trabalho de Kowalski et al. (9), que consistiu na implementação do método juntamente com modificações necessárias e apropriadas para domínios com restrições.

- Proposta de nova métrica de qualidade que avalia o alinhamento de malhas quadrilaterais. 
Esta dissertação está organizada da seguinte forma: no Capítulo 2 apresentamos alguns trabalhos relacionados à geração de malhas de quadriláteros, com o foco em métodos que respeitam o alinhamento da malha em relação às restrições. Nesse capítulo, também damos uma visão geral das métricas de qualidade existentes e concluímos que não existe uma métrica para avaliação de qualidade de alinhamento. No Capítulo 3, explicamos com detalhes o trabalho de Kowalski et al. (9) e as modificações da nossa implementação. No Capítulo 4, propomos uma nova métrica de qualidade que avalia o alinhamento de malhas quadrilaterais. No Capítulo 5, apresentamos as considerações finais, as contribuições e alguns possíveis trabalhos futuros. 


\section{2}

\section{Trabalhos relacionados}

Nesta seção, apresentamos brevemente alguns trabalhos relacionados à geração de malhas de quadriláteros e avaliação de qualidade de malhas de quadriláteros.

\section{1}

\section{Geração de malhas de quadriláteros}

A geração de malhas de quadriláteros é um assunto que já foi muito estudado, porém ainda existem muitos desafios, como, por exemplo, a geração de malhas alinhadas com as restrições (da fronteira e internas) para domínios complexos. $\mathrm{O}$ alinhamento de elementos de uma malha em relação às restrições do domínio é muito importante tanto na área de modelagem (4), para respeitar as formas, quanto na área numérica, para melhor capturar variações do fenômeno físico (18).

O algoritmo paving, introduzido por Blacker e Stephenson (3), enfileira quadriláteros ao longo das restrições (externas e internas) e avança com essa fileira para o interior do domínio, tratando problemas de interseção de elementos, se houver. O método respeita o alinhamento em relação à geometria e orientação das restrições. Existem vários trabalhos que exploraram o método paving, de Blacker e Stephenson (3). White e Kinney (25) propõem um método em que a geração da malha é realizada elemento a elemento e não linha a linha, como no original. Recentemente, Park et al. (15) possibilitam a aplicação do método paving em domínios que têm restrições não-fechadas (open boundary).

Para tratar domínios com restrições complexas, Araújo e Celes (1) apresentam um método automático para geração de malhas de quadriláteros chamado de geração a posteriori, em que restrições do domínio são inseridas iterativamente na malha. Para isso, o método parte de uma malha triangular que é deformada localmente para satisfazer cada restrição inserida. Após as inserções, utilizam-se algumas heurísticas para transformar a malha triangular em uma malha quadrilateral. Pochet et al. (16) propõem um método direto para geração de malhas de quadriláteros, recebendo como entrada um conjunto de restrições geométricas. Em seguida utilizam a estrutura quadtree para adaptar e subdividir o domínio em torno das restrições. Esses dois métodos, no entanto, 
assumem um alinhamento da malha com as direções cartesianas.

Métodos de mapeamento direto garantem alinhamento, mas precisam que o domínio seja particionado. Muitos trabalhos usam o eixo medial ou esqueleto para subdividir o domínio (19). Entretanto, o eixo medial não é estável: uma mudança pequena no domínio pode influenciar muito no esqueleto. Além disso, as regiões geradas normalmente não têm quatro lados, então não são totalmente adequadas para gerar malhas de quadriláteros estruturadas.

Ray et al. (17) apresentam o conceito de n-symmetry direction field, que é um campo com direções invariantes em $\frac{2 \pi}{N}$ rotações. Para $N=1$, temos um campo vetorial; $N=2$ um campo de linha e $N=4$ um campo de cruz (14). Bommes et al. (5), Tarini et al. (20) e Kowalski et al. $(9,10,11)$ utilizam esse conceito de campo de cruz para particionar um domínio no plano ou no espaço em regiões adequadas para geração de malhas de quadriláteros ou hexaedros. A partir de uma malha de triângulos ou tetraedros, eles geram um campo de direcionalidade que preserva as informações das restrições e do domínio. Com as informações desse campo, é possível gerar linhas que vão subdividir o domínio em regiões que são sempre quadrilaterais. Uma vez subdividido o domínio, gera-se a malha de quadriláteros usando um método de mapeamento direto, como o mapeamento transfinito bilinear. Neste trabalho, exploramos essa ideia de partição do domínio a partir do campo de direcionalidade, usando como base os trabalhos de Kowalski et al. no plano (9) e no espaço (11).

Miranda e Martha (8) apresentam um método para gerar malhas de quadriláteros baseado em uma decomposição hierárquica de domínio, em que ao chegar no último nível é possível gerar elementos quadrilaterais usando uma estratégia de mapeamento convencional. Algoritmos de mapeamento direto impõem a restrição de que o número de subdivisões de duas curvas de bordo opostas devem ser iguais. O método proposto por Miranda e Martha elimina essa restrição.

\section{2}

\section{Métricas de qualidade de malhas de quadriláteros}

Existem diferentes formas de avaliar a qualidade de uma malha de quadriláteros. A mais intuitiva é avaliar a valência de cada vértice, ou seja, o número de arestas incidentes em cada vértice. Para que uma malha de quadriláteros seja regular, a valência de todos os vértices deveria ser 4. Assim, muitos trabalhos analisam o quanto as malhas geradas estão próximas de serem regulares (1).

Uma outra métrica de qualidade é calcular o ângulo mínimo formado entre as arestas que definem cada quadrilátero. O que se espera avaliar é a 
quantidade de elementos que têm um ângulo mínimo mais perto de $90^{\circ}$, pois isso significa que os elementos estão mais perto de serem quadrados $(1,9)$.

A métrica de qualidade Jacobiana é utilizada em elementos finitos e é usada para analisar o desvio de um dado elemento da malha em relação a um elemento ideal. Os valores Jacobianos estão no intervalo [-1,1], onde 1 representa um elemento ideal. Para analisar o valor Jacobiano de um elemento basta mapear as coordenadas paramétricas do elemento ideal para as coordenadas globais onde o elemento real é definido. O determinante do Jacobiano está relacionado com o quanto o elemento se deformou para ir das coordenadas paramétricas para as coordenadas globais (9).

O trabalho de Pochet et al. (16) utiliza outra métrica de qualidade, que avalia o fator de distorção. Para cada elemento, calcula-se o desvio $\delta_{i}$ entre $90^{\circ}$ e cada ângulo $\theta_{i}$. O fator de distorção é $f=\sqrt{\sum_{i} \delta_{i}^{2}}$. O melhor fator de distorção é $f=0$, pois um quadrilátero perfeito tem seus quatro ângulos iguais a $90^{\circ}$. Por outro lado, se um elemento é deformado, seus ângulos terão $\delta_{i}=90^{\circ}$, então $f=\pi$. Assim, $f \in[0, \pi]$ e um elemento terá boa qualidade se $f=\frac{\pi}{2}$.

A Tabela 2.1, extraída de (2), lista diferentes métricas de qualidade para elementos em malhas de quadriláteros.

\begin{tabular}{l|c|c|c} 
Métrica & Dimensão & Intervalo & Intervalo Aceitável \\
\hline Razão de Aspecto & $L^{0}$ & {$[1, \infty]$} & {$[1,4]$} \\
Inclinação & $L^{0}$ & {$[0,1]$} & {$[0,0.5]$} \\
Taper & $L^{0}$ & {$[0, \infty]$} & {$[0,0.7]$} \\
Warpage & $L^{0}$ & {$[0,1]$} & {$[0.9,1.0]$} \\
Área & $L^{2}$ & {$[-\infty, \infty]$} & nenhum \\
Esticamento & $L^{0}$ & {$[0,1]$} & {$[0.25,1.0]$} \\
Ângulo Mínimo & graus & {$[0,90]$} & {$[45,90]$} \\
Ângulo Máximo & graus & {$[90,360]$} & {$[90,135]$} \\
Número de Condição & $L^{0}$ & {$[1, \infty]$} & {$[1,4]$} \\
Jacobiano & $L^{2}$ & {$[-\infty, \infty]$} & nenhum \\
Jacobiano Escalado & $L^{0}$ & {$[-1,1]$} & {$[0.5,1.0]$} \\
Cisalhamento & $L^{0}$ & {$[0,1]$} & {$[0.3,1.0]$} \\
Formato & $L^{0}$ & {$[0,1]$} & {$[0.3,1.0]$} \\
Tamanho Relativo & $L^{0}$ & {$[0,1]$} & {$[0.3,1.0]$} \\
Cisalhamento \& Tamanho & $L^{0}$ & {$[0,1]$} & {$[0.2,1.0]$} \\
Formato \& Tamanho & $L^{0}$ & {$[0,1]$} & {$[0.2,1.0]$} \\
Distorção & $L^{2}$ & {$[-1,1]$} & {$[0.6,1.0]$}
\end{tabular}

Tabela 2.1: Métricas de qualidade para malhas de quadriláteros (2).

Na tabela, vemos a dimensão, o intervalo de valores possíveis e o intervalo de valores aceitáveis para que seja considerada uma malha com boa qualidade. Cada métrica é descrita a seguir: 
- Razão de Aspecto: Maior razão entre os tamanhos das arestas de um quadrilátero.

- Inclinação: Maior $|\cos A|$, em que $A$ é o ângulo entre as arestas de um quadrilátero.

- Taper: Maior razão entre os tamanhos das arestas opostas de um quadrilátero.

- Warpage: Cosseno do menor ângulo dihedral formado pelos planos em diagonais que se interceptam.

- Área: Jacobiano.

- Esticamento: Raiz quadrada da razão entre a aresta de menor tamanho e a diagonal de menor tamanho.

- Ângulo Mínimo: Menor ângulo interno.

- Ângulo Máximo: Maior ângulo interno.

- Número de Condição: Maior número de condição da matriz Jacobiana.

- Jacobiano: Volume mínimo do mapeamento entre os cantos e o centro do quadrilátero.

- Jacobiano Escalado: Menor Jacobiano dividido pelo tamanho dos dois vetores da aresta.

- Cisalhamento: 2/Número de condição da matriz Jacobiana antissimétrica.

- Formato: 2/Número de condição da matriz Jacobiana com peso.

- Tamanho Relativo: $\min (J, 1 / J)$, onde $J$ é determinante da matriz Jacobiana com peso.

- Cisalhamento \& Tamanho: Produto entre o cisalhamento e o tamanho relativo.

- Formato \& Tamanho: Produto entre o formato e o tamanho relativo.

- Distorção: $4 \min (|J|) /$ área atual

Todas essas métricas são locais, avaliando a qualidade dos elementos localmente, sem avaliar a malha globalmente. Nenhuma dessas métricas avalia o alinhamento da malha. Este trabalho propõe uma nova métrica para avaliar alinhamento da malha com as restrições do domínio, que será explicada no Capítulo 4. 


\section{3 \\ Partição do domínio em regiões quadrilaterais}

A primeira etapa deste trabalho consistiu em revisitar o trabalho de Kowalski et al. (9). Neste capítulo explicaremos com detalhes o método original proposto em (9) e explicaremos as alterações que fizemos na nossa implementação. A seguir, discutiremos os resultados obtidos.

O artigo de Kowalski et al. (9) apresenta um algoritmo para particionar um domínio $\Omega$ no plano em regiões apropriadas para a geração de malhas de quadriláteros. A partir de uma triangulação uniforme do domínio $\Omega$, o algoritmo se divide nas seguintes etapas, ilustradas na Figura 3.1:

a,b: Geração de um campo de direcionalidade de $\Omega$, resolvendo uma equação diferencial parcial para propagação dos vetores de representação.

c: Localização das singularidades do campo e das separatrizes que as conectam, particionando $\Omega$ em regiões quadrilaterais.

d: Geração de uma malha de quadriláteros por um mapeamento estruturado em cada região quadrilateral.

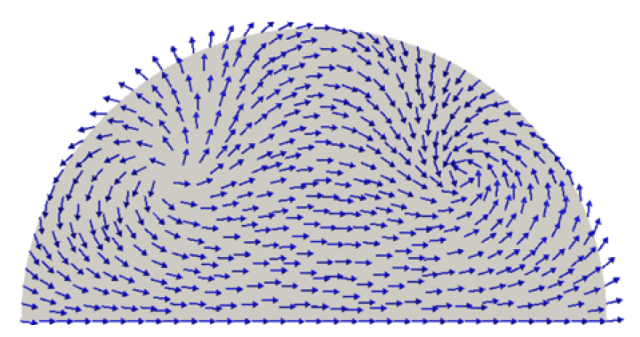

(a) Vetores de representação.

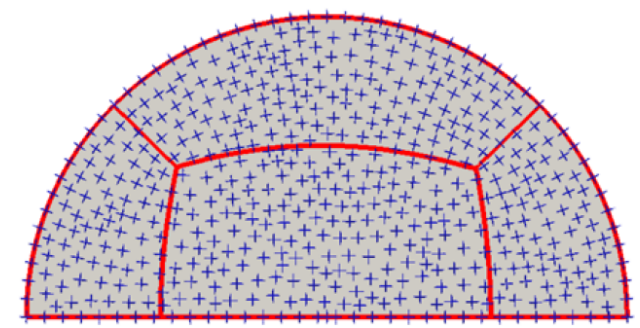

(c) Partição em regiões quadrilaterais.

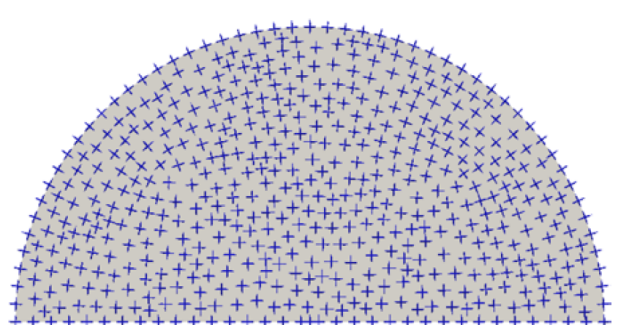

(b) Campo de direcionalidade.

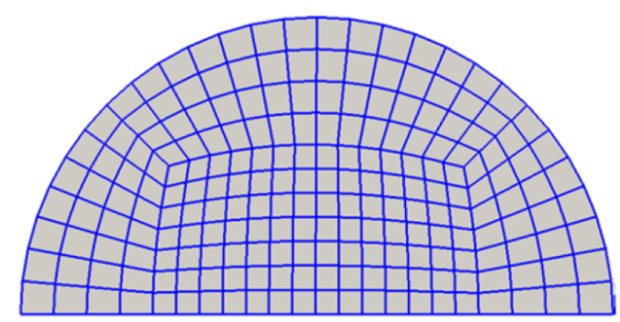

(d) Malha de quadriláteros.

Figura 3.1: As etapas do método de Kowalski et al. (9). 


\section{1}

\section{Campo de direcionalidade}

Kowaslki et al. (9) apresentam o conceito de direcionalidade (directionality), que guia o seu trabalho. A criação de um campo de direcionalidade tem como objetivo propagar as orientações das restrições para o interior do domínio. As restrições são a fronteira do domínio e algumas arestas do interior pré-definidas. A vantagem e uma das razões de se usar a direcionalidade é que ela é contínua nos cantos retos (nem todos os campos vetoriais são contínuos; por exemplo, o campo do vetor tangente) e, consequentemente, contínua em regiões quadrilaterais. Vemos na Figura 3.2 um exemplo de um domínio com as tangentes das restrições, podemos ver a descontinuidade no campo.

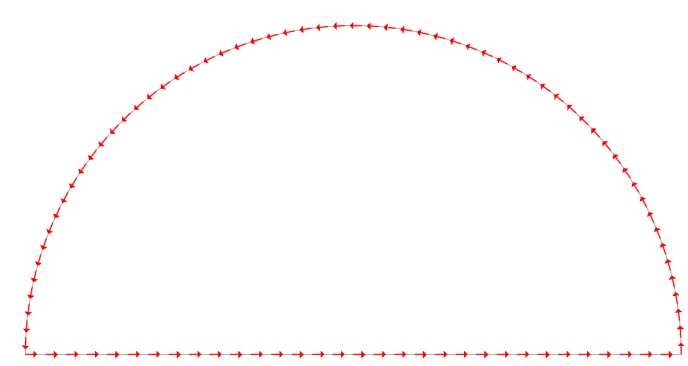

(a)

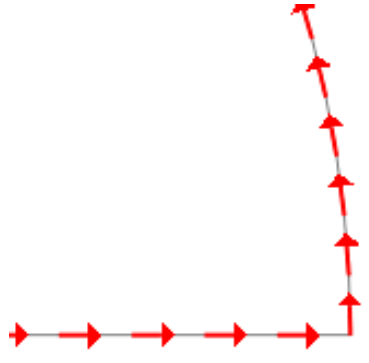

(b)

Figura 3.2: Campo do vetor tangente é descontínuo em segmentos perpendiculares na fronteira do domínio.

Um vértice regular $P$ no interior de uma malha quadrilateral tem valência 4 e as quatro arestas incidentes a $P$ podem ser vistas como dois conjuntos de arestas opostas. $P$ é a interseção dos dois conjuntos, que podem ser vistos como uma discretização de uma curva. As tangentes dessas curvas em $P$ podem ser descritas como uma cruz.

Obtêm-se um ângulo $\theta$ entre uma dessas tangentes e uma direção fixa (Kowaslki et al. (9) escolheram como direção de referência a direção do eixo $x$ ). Um novo vetor é construído usando $\theta$ :

$$
\vec{v}_{0}=(\cos \theta, \sin \theta)
$$

A partir do vetor $\vec{v}_{0}$ é possível construir a direcionalidade. A direcionalidade correspondente ao ângulo $\theta \in\left[0, \frac{\pi}{2}\right)$ é definida como:

$$
C_{\theta}=\left\{\vec{v}_{k}=\left(\cos \left(\theta+\frac{k \pi}{2}\right), \sin \left(\theta+\frac{k \pi}{2}\right)\right)^{T}, 0 \leq k \leq 3\right\}
$$

Dado o ângulo $\theta$ referente a $\vec{v}_{0}$, os ângulos dos vetores seguintes $\vec{v}_{1}, \vec{v}_{2}, \vec{v}_{3}$ são construídos da seguinte forma: 


$$
\theta_{k+1}=\left(\theta_{k}+\frac{\pi}{2}\right) \bmod 2 \pi \quad \text { onde } \quad \theta_{0}=\theta, \quad 0 \leq k \leq 2
$$

Assim, a direcionalidade tem formato de uma cruz, pois os vetores consecutivos são ortogonais entre si já que seus ângulos diferem por $\frac{\pi}{2}$. A Figura 3.3 ilustra a direcionalidade na fronteira; vemos que a direcionalidade é contínua nos cantos retos.

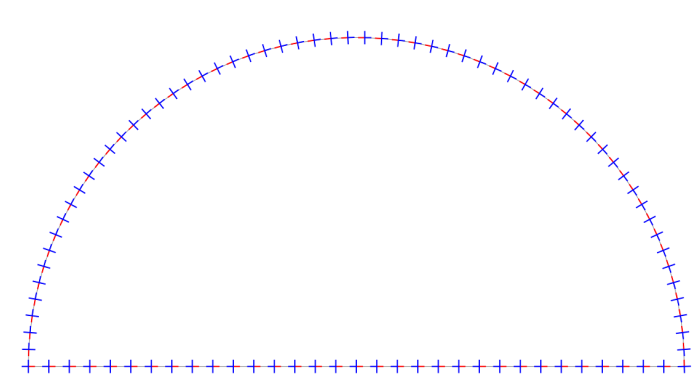

(a)

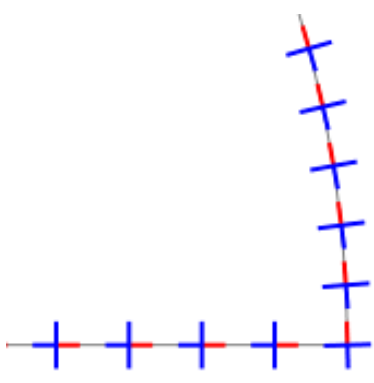

(b)

Figura 3.3: A direcionalidade é contínua em segmentos perpendiculares na fronteira do domínio. O vetor $\vec{v}_{0}$ está destacado em vermelho.

Como a direcionalidade é composta por quatro vetores, isso dificulta o cálculo de interpolação. Para facilitar, Kowaslki et al. (9) criaram uma representação vetorial da direcionalidade, chamada de vetor de representação (representation vector). O mapeamento entre o vetor de representação e a direcionalidade é feito usando os ângulos descritos acima. A fórmula que converte a direcionalidade $C_{\theta}$ em seu vetor de representação $\vec{v}_{r}$ é:

$$
\vec{v}_{r}=\left(\cos \left(\theta_{r}\right), \sin \left(\theta_{r}\right)\right) \quad \text { onde } \quad \theta_{r}=\left(4 \theta_{k}\right) \bmod 2 \pi, \quad 0 \leq k \leq 3
$$

Isto é, $\theta_{r}$ é o ângulo que o vetor de representação da direcionalidade faz com o eixo de referência (eixo $x$, no caso). Isso significa que o $\theta$ usado na Equação 3-2 é $\theta=\frac{\theta_{r}}{4}$ (pois $\left.k=0\right)$.

Assim, quando um vetor de representação sofre uma rotação de $2 \pi$, a sua direcionalidade sofre apenas uma rotação de $\frac{\pi}{2}$. Note que o vetor de representação tem continuidade em segmentos perpendiculares na fronteira do domínio, pois o vetor de representação tem orientação igual a $4 \theta$, sendo $\theta$ o ângulo entre os segmentos de reta e o eixo $x$. A Figura 3.4 ilustra os vetores de representação nas restrições e sua continuidade nos cantos retos. 


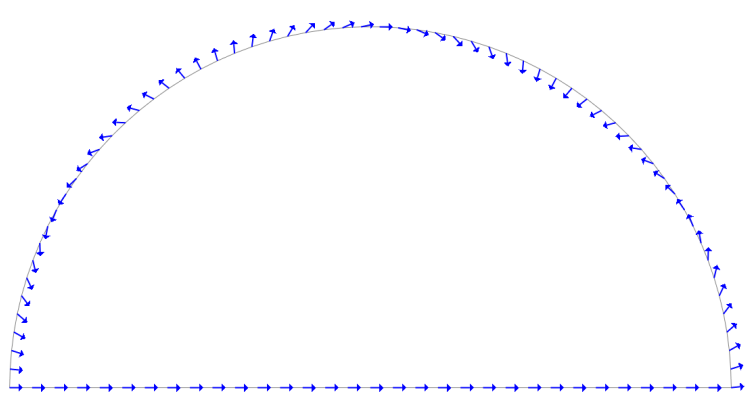

(a)

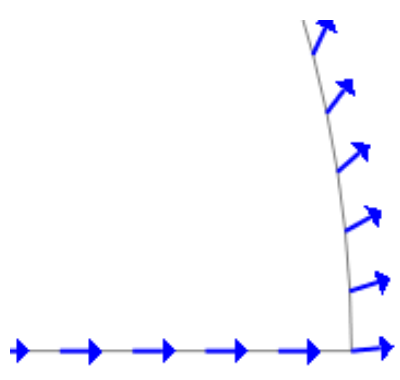

(b)

Figura 3.4: O vetor de representação é contínuo em segmentos perpendiculares na fronteira do domínio.

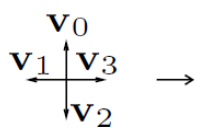

(a)

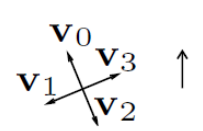

(b)

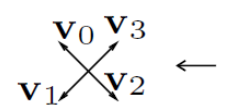

(c)

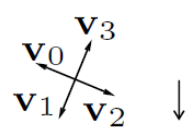

(d) $\underbrace{\mathbf{v}_{0}}_{\mathbf{v}_{1} \mathbf{v}_{2}} \rightarrow$

(e)

Figura 3.5: Exemplos de direcionalidade e seus vetores de representação (9).

Na Figura 3.5 podemos ver exemplos de direcionalidades e vetores de representação. Vemos que os vetores de representação em (a) e em (e) são iguais, embora tenham direcionalidades diferentes.

Kowalski et al. (9) usam o conceito de direcionalidade para propagar as informações das restrições (fronteira) para todo o domínio. Kowalski et al. (9) resolvem um problema de difusão para realizar essa propagação. Para isso, eles resolvem uma equação diferencial parcial a partir do método dos elementos finitos, descrita pela Equação 3-5, com o objetivo de minimizar $J(u)$. A solução será $u(x)$, que é uma função vetorial. É importante ressaltar que essa equação impõe a restrição de que os vetores devem ser unitários.

$$
\left\{\begin{array}{l}
J(u)=\int_{\Omega}|\nabla u|^{2} d x \\
u(x)=u_{0}(x) \quad \forall x \in \partial \Omega \\
|u(x)|=1 \quad \forall x \in \Omega
\end{array}\right.
$$

\section{2}

\section{Singularidades}

O próximo passo do método de Kowalski et al. (9) é analisar a topologia do campo de direcionalidade, encontrar as singularidades do campo e calcular as separatrizes que têm início nessas singularidades.

Uma singularidade ocorre onde o campo de direcionalidade é indefinido e seu vetor de representação é nulo. Uma singularidade pode estar dentro de um triângulo ou sobre uma aresta. Dado um triângulo $T$ com vértices $P_{1}, P_{2}, P_{3}$, 
seja $v\left(P_{i}\right)$ o vetor de representação em $P_{i}$ e $\theta_{i}$ o ângulo entre $v\left(P_{i}\right)$ e o eixo $x$. O indice de Poincaré $(9,23)$ é dado por

$$
i_{s}=\frac{\Delta \theta_{12}+\Delta \theta_{23}+\Delta \theta_{31}}{2 \pi}
$$

onde $\Delta \theta_{i j}=\theta_{j}-\theta_{i}-\pi$. O triângulo $T$ contém uma singularidade quando $i_{s}= \pm 1$. Quando $i_{s}=0$, o triângulo $T$ não contém uma singularidade.

Para verificar se a singularidade se encontra em uma aresta, o processo é análogo, mas são considerados os dois triângulos que compartilham essa aresta. A Figura 3.6 ilustra esse caso e o índice de Poincaré é calculado pela equação:

$$
i_{s}=\frac{\Delta \theta_{13}+\Delta \theta_{32}+\Delta \theta_{24}+\Delta \theta_{41}}{2 \pi}
$$

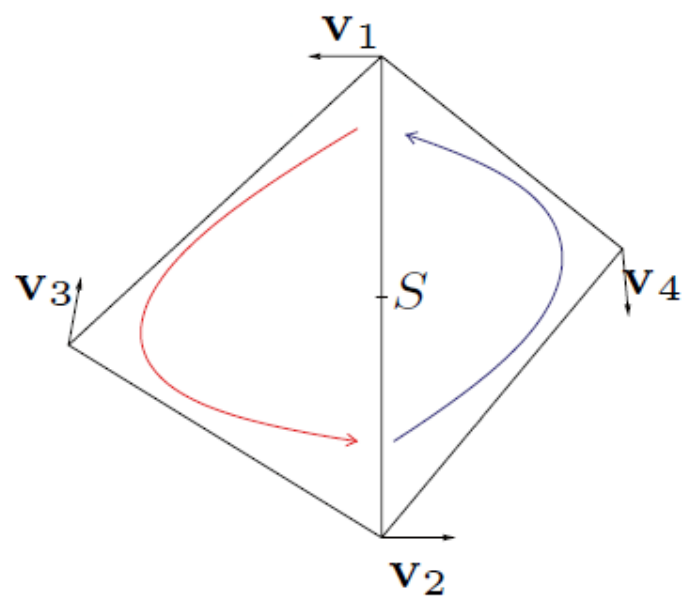

Figura 3.6: Se a singularidade está em uma aresta, são considerados os dois triângulos que a contém.

\section{3}

\section{Separatrizes}

A etapa após encontrar as singularidades é definir as separatrizes que irão determinar as regiões quadrilaterais. Separatrizes são linhas de corrente (streamlines) que têm início num ponto de singularidade. Uma linha de corrente é uma curva cuja tangente em qualquer ponto da curva tem a mesma direção que o campo vetorial nesse ponto. No nosso caso, as linhas de corrente estão relacionadas à direcionalidade. Assim, para qualquer linha de corrente e um ponto dessa linha temos que a tangente nesse ponto terá a mesma direção de um dos vetores da direcionalidade nesse ponto.

Para iniciar a geração de uma separatriz é necessário achar o ponto que ela intercepta a aresta do triângulo que contém a singularidade. Dados uma aresta $e$ de um triângulo $T$ que contém uma singularidade $S_{o}$, um ponto $P$ 
em $e$ e o vetor $\vec{u}=P-S_{o}$, temos que a separatriz intercepta $e$ em $P$ quando um dos vetores $\vec{v}_{k}$ da direcionalidade de $P$ tiver a mesma direção e sentido do que o vetor $\vec{u}$; como ilustrado pela Figura 3.7.

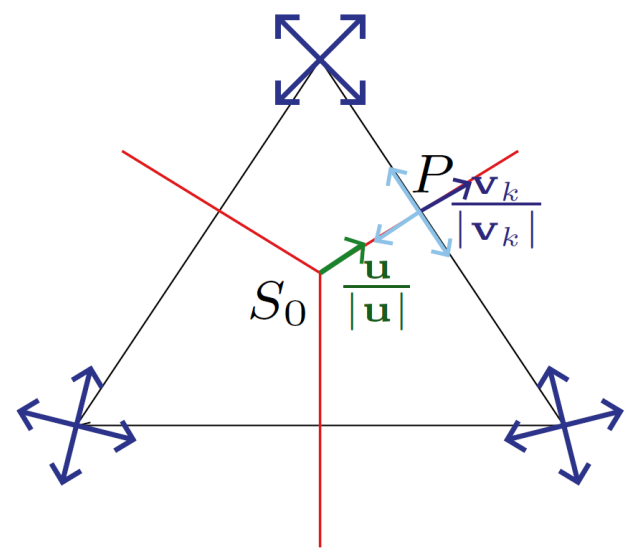

Figura 3.7: Interseção das separatrizes de $S_{0}$ com o triângulo que ela pertence (9).

A partir dos dois vértices que compõe a aresta $e$ e das suas respectivas direcionalidades, é possível obter seus vetores de representação e, com eles, realizar uma interpolação linear para definir $\vec{v}_{k}$ em $P$. Em seguida, pode-se verificar se $\vec{v}_{k}$ tem a mesma direção e sentido do que $\vec{u}$. Se tiver, temos que $P$ é o ponto que liga a singularidade $S_{0}$ com a aresta $e$, formando o início da separatriz. A partir de uma singularidade podem sair três ou cinco separatrizes, dependendo do valor do índice de Poincaré da singularidade. Se o índice for +1 , sairão três separatrizes; se o índice for -1 sairão cinco separatrizes.

Uma vez obtido o início de cada separatriz, o próximo passo é gerar os próximos segmentos que compõe a separatriz. Esse processo é feito utilizando um método de integração numérica. Kowalski et al. (9) usam o método de Heun, que é uma variação do método de Runge-Kutta de segunda ordem (7), ilustrado na Figura 3.8.

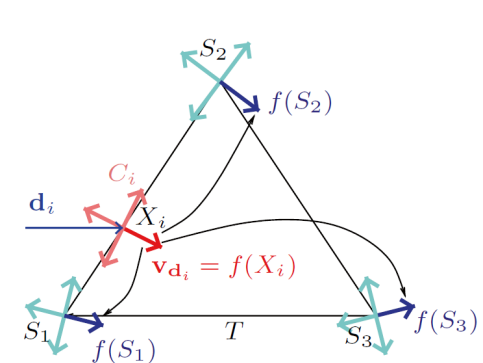

(a)

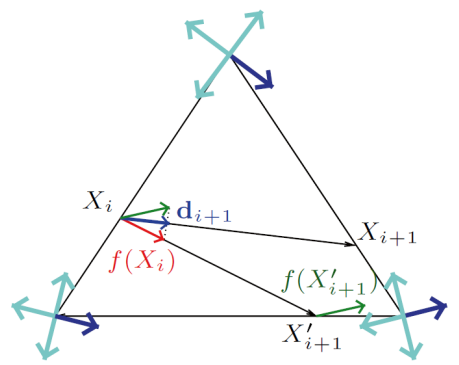

(b)

Figura 3.8: Processo de integração nos triângulos para definir as separatrizes (9). 
A proposta do método é integrar pelos triângulos. Assim, cada passo da integração tem início em um ponto de um triângulo e fim em outro ponto desse mesmo triângulo. Cada passo da integração se inicia em um ponto $X_{i}$ que está localizado em uma aresta de um triângulo $T$. Esse ponto tem uma direção $\vec{d}_{i}$ de entrada e o objetivo é calcular a direção $\vec{d}_{i+1}$ de saída de $T$ no ponto $X_{i+1}$.

$O$ vetor de representação em $X_{i}$ é calculado por interpolação linear dos vetores de representação nos vértices da aresta de $T$ contendo $X_{i}$. Uma vez calculado o vetor de representação, temos a direcionalidade $C_{i}$ em $X_{i}$. É então definido um campo vetorial $Y=f(X)$ ao longo de $T$, que é o vetor de cada direcionalidade ao longo de $T$ que tem menor ângulo em relação à direção $\vec{d}_{i}$ denominado $v_{\vec{d}_{i}}$.

Sendo $v_{\vec{d}_{i}}=f\left(X_{i}\right)$, para achar o ponto $X_{i+1}$ de saída, é necessário encontrar um ponto intermediário $X_{i+1}^{\prime}$ :

$$
X_{i+1}^{\prime}=X_{i}+h f\left(X_{i}\right)
$$

A partir de $f\left(X_{i+1}^{\prime}\right)$ e $f\left(X_{i}\right)$, é possível encontrar a direção de saída, $\vec{d}_{i+1}$ :

$$
\vec{d}_{i+1}=\frac{f\left(X_{i}\right)+f\left(X_{i+1}^{\prime}\right)}{2}
$$

Assim:

$$
X_{i+1}=X_{i}+h \vec{d}_{i+1}
$$

A Figura 3.8 ilustra esse processo, que é feito a cada iteração gerando, uma separatriz ao final. A integração termina quando a linha de corrente atinge outra singularidade ou ao chegar na fronteira.

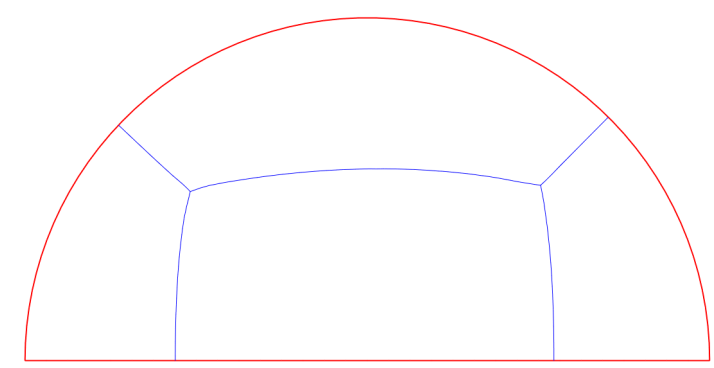

Figura 3.9: Resultado da partição de um domínio em regiões quadrilaterais. Vemos suas as restrições em vermelho e em azul as separatrizes ao final da integração.

\subsection{1}

\section{Combinação de separatrizes}

Quando uma separatriz começa em uma singularidade $S_{0}$ e termina em outra singularidade $S_{1}$, são geradas duas separatrizes: uma de $S_{0}$ até $S_{1}$ e outra de $S_{1}$ até $S_{0}$. Devido a erros de precisão na integração numérica, as separatrizes 
não são idênticas. Por isso, substituímos essas duas separatrizes por uma nova separatriz que é a combinação delas.

Como cada separatriz tem precisão maior o quanto mais perto estiver da singularidade que a originou, Kowalski et al. (9) propõem uma combinação linear das duas separatrizes baseada na distância que elas estão da singularidade que as originou.

Dada uma parametrização $\gamma_{1}(t), t \in[0,1]$ da separatriz de $S_{0}$ para $S_{1}$ e uma parametrização $\gamma_{2}(t), t \in[0,1]$ da separatriz de $S_{1}$ para $S_{0}$, a combinação delas será a separatriz $\gamma_{c}(t)$ indo de $S_{0}$ para $S_{1}$ dada pela parametrização:

$$
\gamma_{c}(t)=(1-t) \gamma_{1}(t)+t \gamma_{2}(1-t)
$$

\subsection{2}

\section{Raio de influência}

No trabalho original, Kowalski et al. (9) interrompem o traçado de uma linha de corrente quando ela intercepta um triângulo que tem singularidade. Posteriormente, quando estenderam o trabalho para 3D, Kowalski et al. (11) optaram por usar um raio de influência das singularidades. A linha é então interrompida quando intercepta o círculo (esfera em 3D), como ilustrado na Figura 3.10. O raio de influência força o pareamento entre singularidades independente da resolução da malha, trazendo estabilidade.

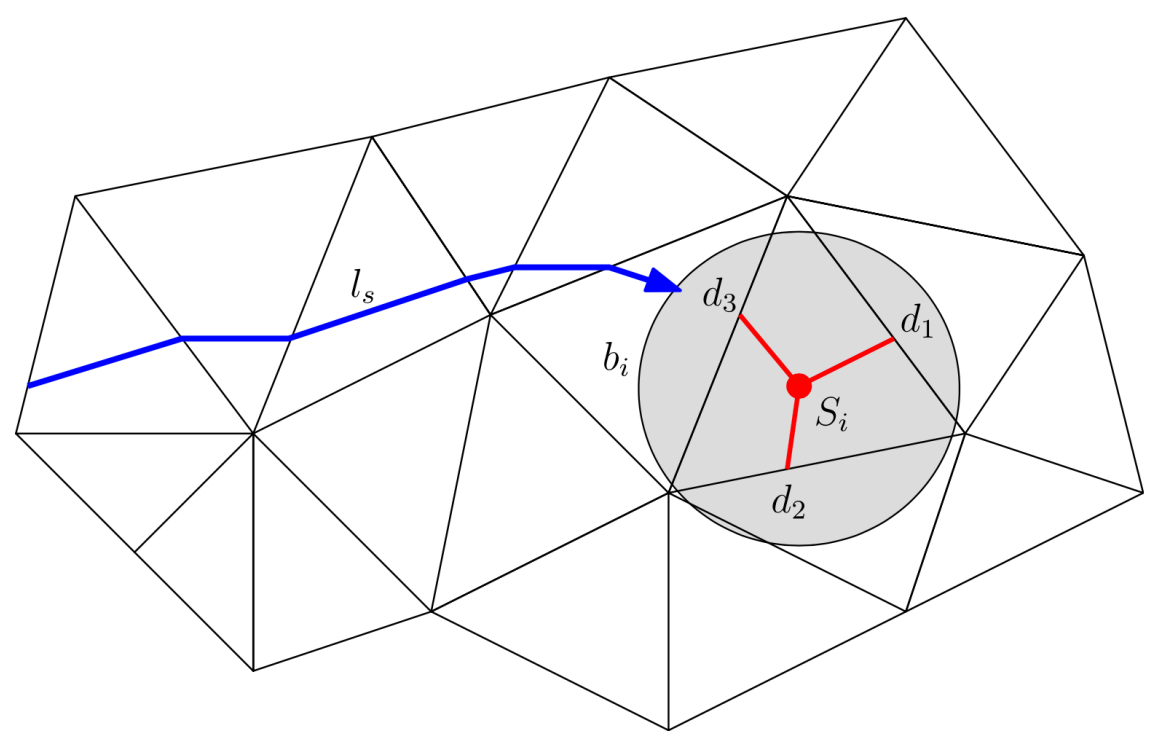

Figura 3.10: Caso em que uma singularidade encontra um raio de influência (11). 


\section{4}

\section{Geração da malha de quadriláteros}

Para gerar regiões quadrilaterais, são adicionadas as chamadas singularidades geométricas, que são os cantos da fronteira de $\Omega$. A partir dessas singularidades, são criadas separatrizes utilizando o mesmo processo para as singularidades do campo do vetor de representação.

Com isso, o conjunto de separatrizes das singularidades tanto do campo quanto as geométricas resulta em uma partição do domínio $\Omega$ em regiões quadrilaterais. Isso é possível pois as regiões encontradas não contêm singularidades em seu interior, somente em seus cantos. Assim, é possível realizar uma parametrização $f(v, u)$ tanto no interior das regiões, como em suas fronteiras devido à continuidade. $\mathrm{O}$ único caso em que isso falha é quando existe uma aresta degenerada (tamanho nulo), gerando uma região triangular, como mostra a Figura 3.11.

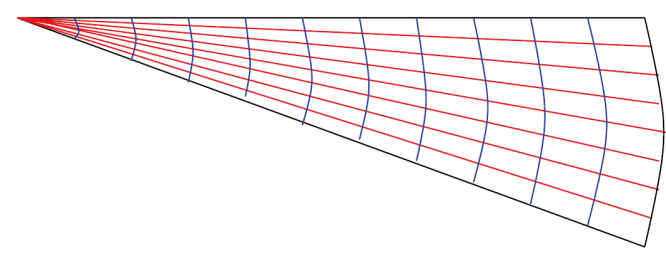

Figura 3.11: Região triangular (9).

Se esse caso de degeneração de aresta não existir, a região pode ser parametrizada por uma função de mapeamento $f(u, v)$ com $u, v \in[0,1]$, como ilustrado pelas quatro regiões da Figura 3.12.

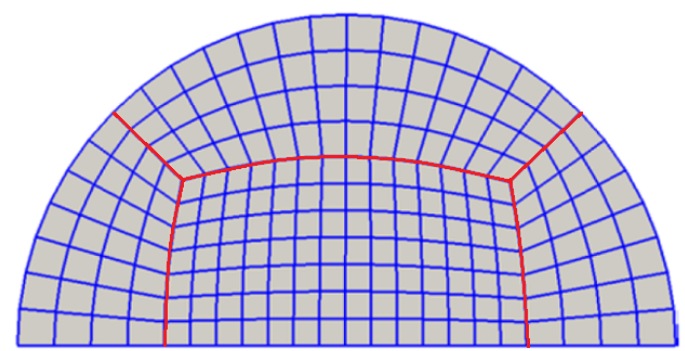

Figura 3.12: Malha de quadriláteros gerada pelo método de Kowalski et al. (9).

\section{5}

\section{Implementação e Resultados}

Nesta seção vamos explicar como implementamos o método de Kowalski et al. (9), discutindo as adaptações que fizemos nos vários passos. Utilizamos a biblioteca TopS (6) para representar a malha dos modelos. Tops é uma 
estrutura de dados topológica compacta desenvolvida para a representação de malha de elementos finitos. Nessa estrutura, somente os nós e os elementos são representados explicitamente. Além disso, todas as adjacências topológicas podem ser recuperadas em um tempo proporcional ao número de entidades recuperadas.

\subsection{1}

\section{Campo de direcionalidade}

Usamos o mesmo conceito de direcionalidade e de vetor de representação. Assim, temos que resolver o mesmo problema de propagar as informações das restrições para todo domínio. No nosso trabalho, consideramos como restrições tanto a fronteira do domínio quanto arestas no interior, como mostra a Figura 3.13.

Para iniciar a propagação, os vetores de representação das restrições são calculados como a média dos vetores de representação das duas arestas que são incidentes a cada vértice e que também são restrições. O vetor de representação de cada aresta é calculado a partir de sua direcionalidade, que é composta pela normal e pela tangente da aresta. Por fim, os vetores são normalizados. Para vértices com mais de duas arestas incidentes, não prescrevemos valor de representação, tratando-os como vértices internos.

Propagamos as informações das restrições para todo o domínio usando o programa gHEM (21) para simular difusão. O gHEM resolve um problema de condução de calor (difusão) baseado na conservação de energia de uma amostra infinitesimal e utiliza as equações descritas no trabalho de Wang e Mai (24). Usamos o gHEM para propagar os vetores de representação das restrições do domínio por componente, tanto componente $x$, quanto componente $y$. A gHEM recebe como entrada uma malha triangular e os

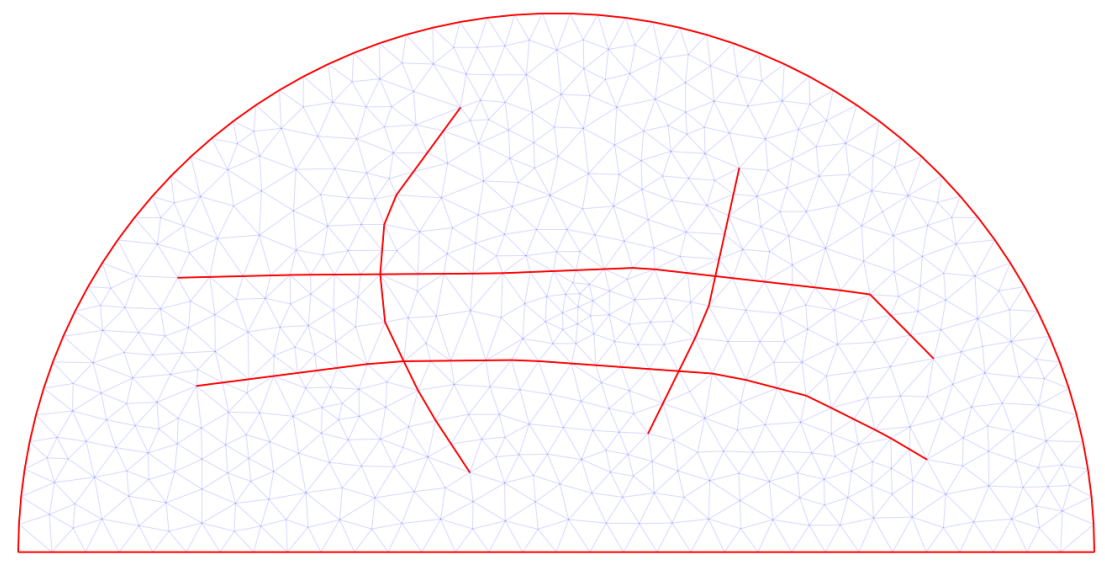

Figura 3.13: Modelo com restrições tanto na fronteira quanto no interior. 
valores escalares (componentes do vetor de representação) nos vértices das restrições, representando a temperatura. Usamos o programa Pos3D (22) para visualizar o resultado do campo escalar gerado para cada componente, como ilustrado na Figura 3.14.

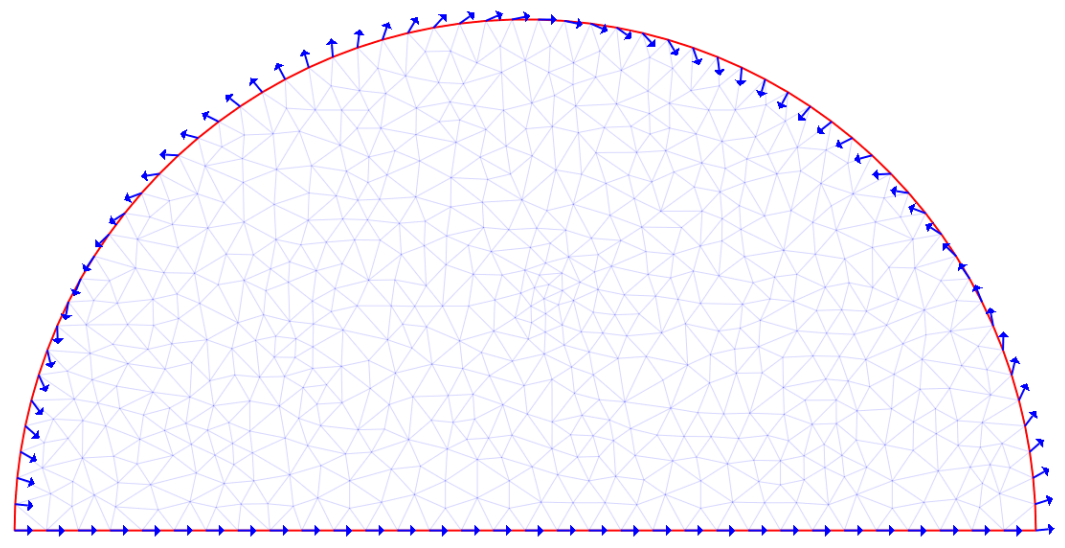

(a) Vetores de representação prescritos a partir das restrições em vermelho.

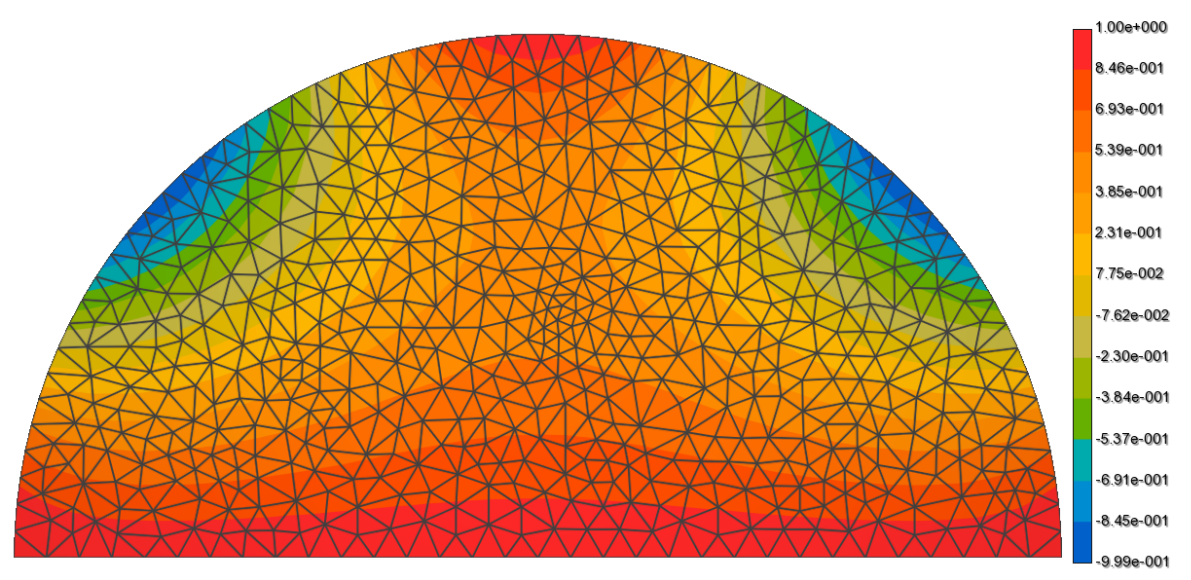

(b) Campo do eixo $x$.

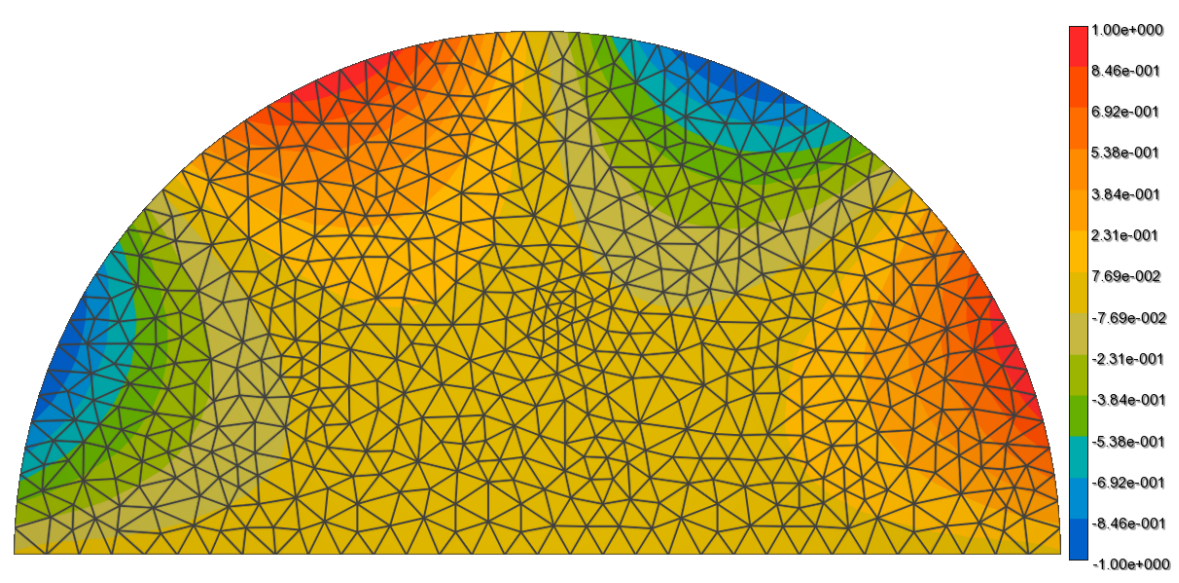

(c) Campo do eixo $y$.

Figura 3.14: Campos do eixo $x$ e do eixo $y$ dos vetores de representação. 
Esse procedimento é diferente do de Kowalski et al. (9). Eles incorporam a restrição de que os vetores devem ser unitários, justificando que deixar a norma variar introduz erros e gera variações nas orientações das direcionalidades. Entretanto, não verificamos essas variações ao usar a difusão com a gHEM componente a componente. Ao final da transferência, temos um valor associado para $x$ e para $y$ que utilizamos para construir o vetor de representação em cada vértice da malha. Sempre que necessário, normalizamos o vetor. No entanto, o vetor não normalizado, resultante da difusão, é importante em diferentes etapas da nossa proposta. A Figura 3.15 ilustra o resultado dessa propagação.

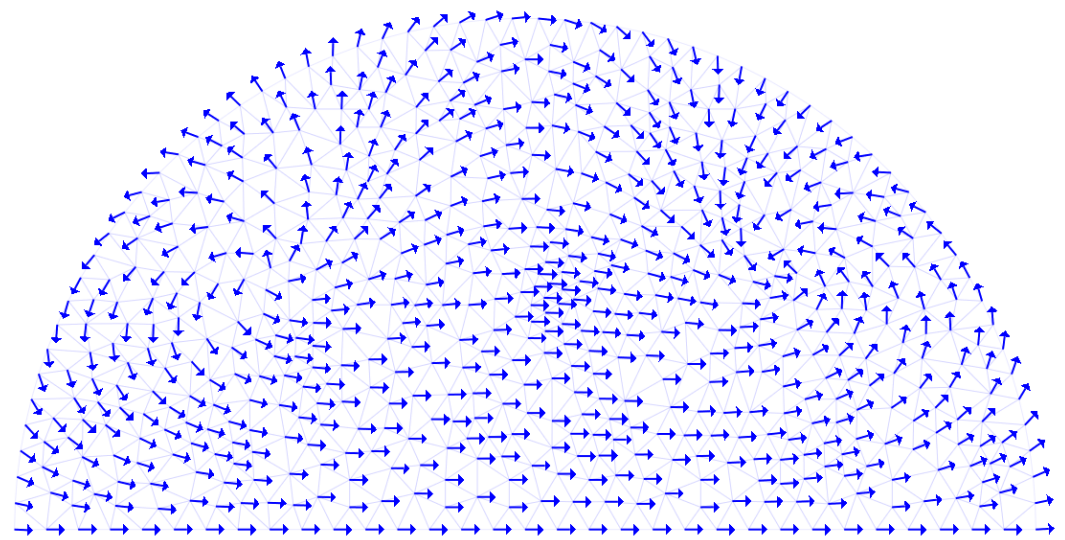

(a) Campo do vetor de representação.

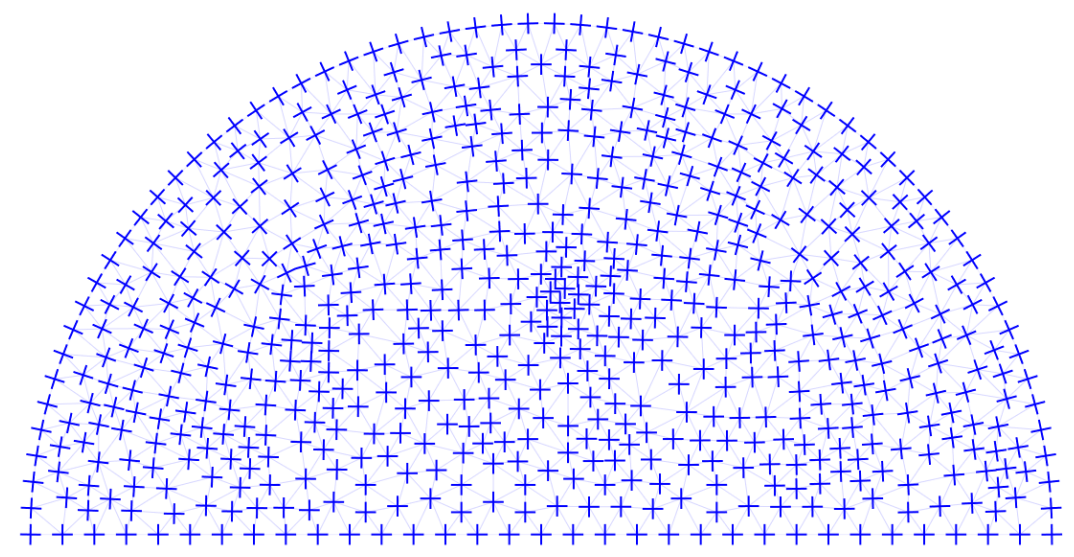

(b) Campo de direcionalidade.

Figura 3.15: Campo do vetor de representação e da direcionalidade. 


\section{5 .2}

\section{Singularidades}

Para definir o valor do campo em um ponto $P$ no interior de um triângulo $A B C$, usamos as coordenadas baricêntricas:

$$
P=\alpha A+\beta B+\gamma C
$$

onde, de acordo com a Figura 3.16,

$$
\alpha=\frac{\text { area } P B C}{\text { area } A B C}, \quad \beta=\frac{\text { area } P C A}{\text { area } A B C}, \quad \gamma=\frac{\text { area } P A B}{\text { area } A B C}
$$

$\mathrm{O}$ vetor $\vec{v}_{p}$ do campo em $P$ é dado por interpolação baricêntrica:

$$
\vec{v}_{P}=\alpha \vec{v}_{a}+\beta \vec{v}_{b}+\gamma \vec{v}_{c}
$$

Na Seção 3.2 definimos que uma singularidade ocorre onde o campo de direcionalidade é indefinido e seu vetor de representação é nulo. Assim, se encontrarmos um triângulo que tenha um ponto no seu interior com vetor de representação nulo, esse ponto será um ponto de singularidade. Usaremos coordenadas baricêntricas para resolver esse problema. Nesse caso, queremos que $\vec{v}_{p}=(0,0)$ para que $P$ seja um ponto de singularidade:

$$
(0,0)=\alpha \vec{v}_{A}+\beta \vec{v}_{B}+\gamma \vec{v}_{C}
$$

Assim, calculamos as coordenadas baricêntricas $\alpha, \beta, \gamma$, do "ponto" $(0,0)$ em relação aos "pontos" $v_{a}, v_{b}, v_{c}$. Se $\alpha, \beta, \gamma \in[0,1]$, então $P=\alpha A+\beta B+\gamma C$ é um ponto de singularidade no triângulo $A B C$.

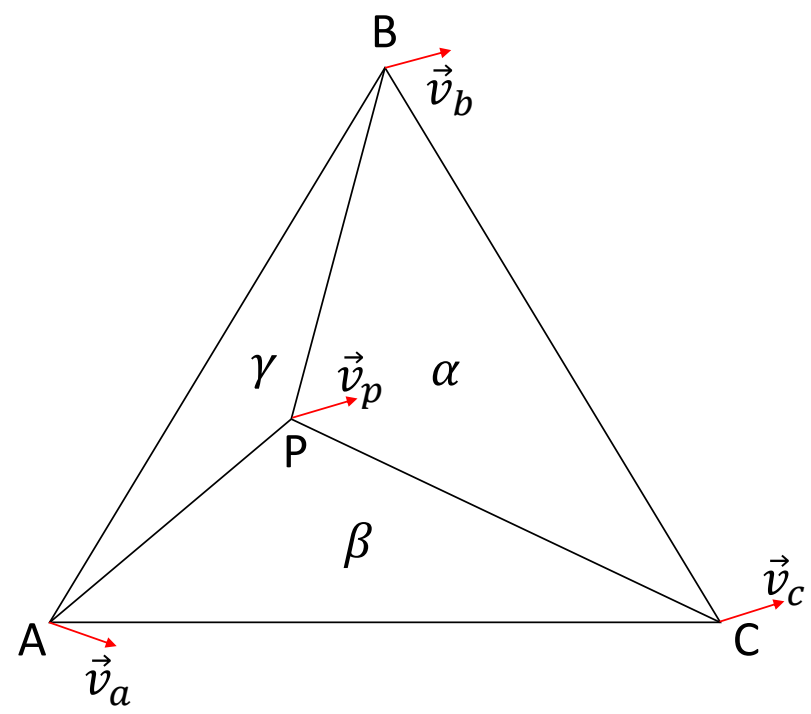

Figura 3.16: Utilizamos as coordenadas baricêntricas para encontrar os pontos de singularidade num triângulo. 
A vantagem de usar esse método em comparação com o de Kowalski et al. (9) é que já obtemos a posição exata do ponto $P$ que tem vetor de representação nulo. Ao usar o método de Kowalski et al. (9), teríamos que calcular a posição do ponto após identificar que o triângulo possui uma singularidade; isso seria um cálculo a mais.

As Figuras (a) e (a) representam a magnitude do vetor de representação, em que a cor vermelha corresponde à magnitude 1 e a cor azul, à magnitude 0 . As Figuras (b) e (b) mostram em laranja os triângulos que foram detectados como tendo uma singularidade em seu interior, usando o método descrito acima.

Com isso, as Figuras 3.17 e 3.18 comparam magnitude do vetor de representação com os pontos de singularidade. Podemos ver que a região azul é a mesma região em que foram detectados triângulos contendo singularidades, o que é esperado já que a região azul é onde a magnitude é nula, que é exatamente a definição de singularidade. Além disso, a região vermelha das Figuras (a) e (a) é exatamente a região da fronteira; isso é coerente pois iniciamos a difusão de temperatura pela fronteira e com magnitude máxima (vetores normalizados).

\subsection{3}

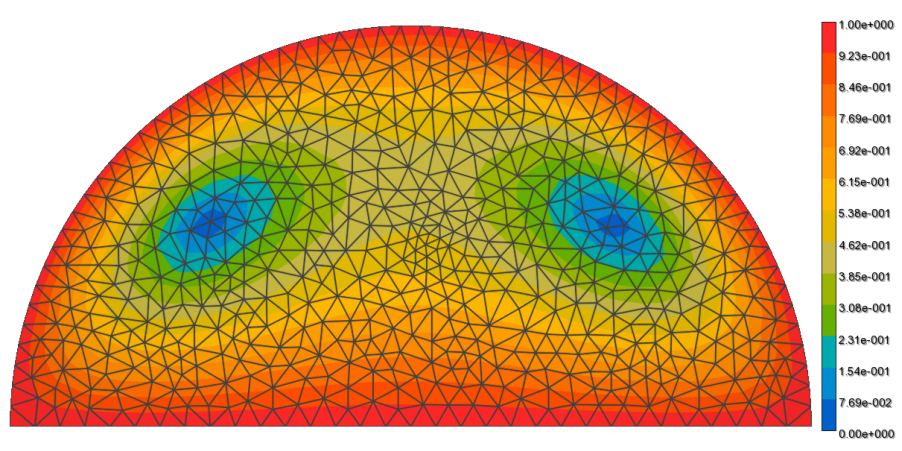

(a) Magnitude do vetor de representação.

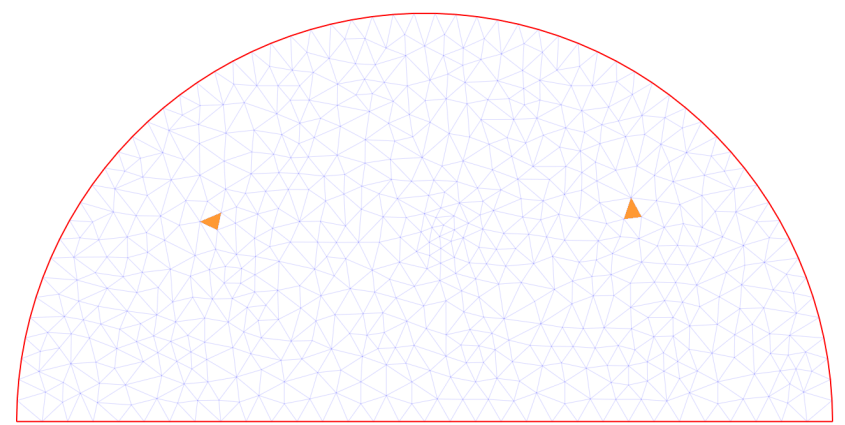

(b) Triângulos que contêm singularidades.

Figura 3.17: A magnitude nula (azul) está relacionada com a região de singularidade. 


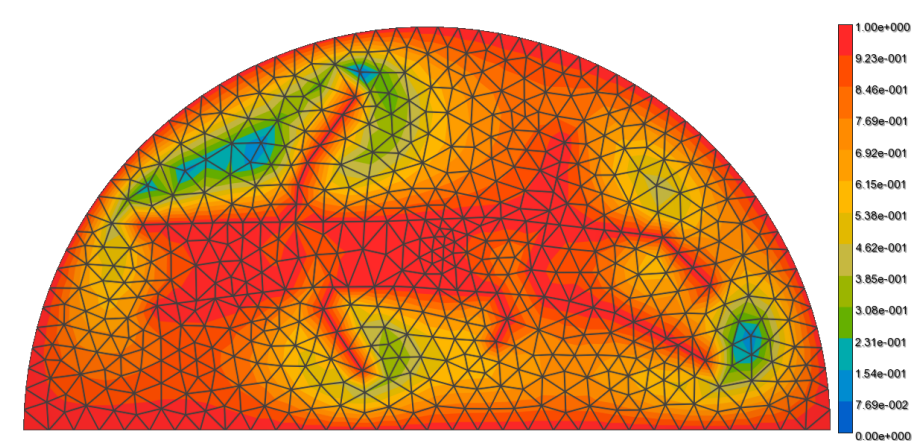

(a) Magnitude do vetor de representação.

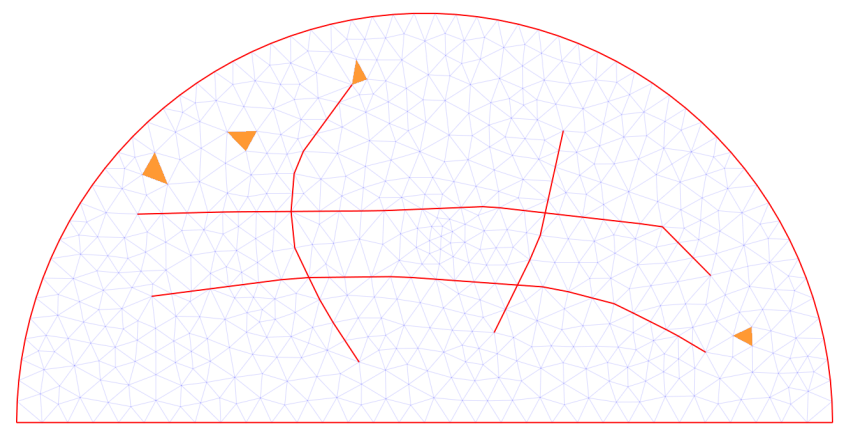

(b) Triângulos que contêm singularidades.

Figura 3.18: A magnitude nula (azul) está diretamente relacionada com a região de singularidade.

\section{Separatrizes}

Para criar as separatrizes, utilizamos a mesma ideia de Kowalski et al. (9), descrita na Seção 3.3. Entretanto, ao invés de usar somente o triângulo que contém a singularidade, usamos os dois triângulos que compartilham a aresta que está mais perto do ponto de singularidade. Então as arestas testadas são todas menos a aresta mais perto da singularidade, como mostra a Figura 3.19. Fizemos isso pois para pontos de singularidade interiores muito próximos a uma das arestas do triângulo, introduzia imprecisão numérica na determinação dos pontos de partida das separatrizes.

Para encontrar o ponto $P$ onde a separatriz da singularidade $S$ intercepta a aresta $e$, devemos encontrar o ponto em que o produto vetorial entre $\overrightarrow{S P}$ e $\vec{v}_{d_{P}}$ seja nulo, pois isso significa que $\overrightarrow{S P}$ e $\vec{v}_{d_{P}}$ têm a mesma direção. $\vec{v}_{d_{P}}$ é um dos vetores da direcionalidade de $P\left(d_{P}\right)$, que é encontrado a partir do vetor de representação de $P$, calculado pela interpolação baricêntrica dos vetores de representação da aresta $e$. Percorremos a aresta $e$ procurando uma mudança de sinal desse produto vetorial. Quando houver mudança de sinal, sabemos que o produto vetorial nulo está nesse intervalo. Então, usamos o método da bisseção (7) nesse intervalo para encontrar o ponto exato. Após obtermos o início de cada separatriz, prolongamos cada uma a partir do método 


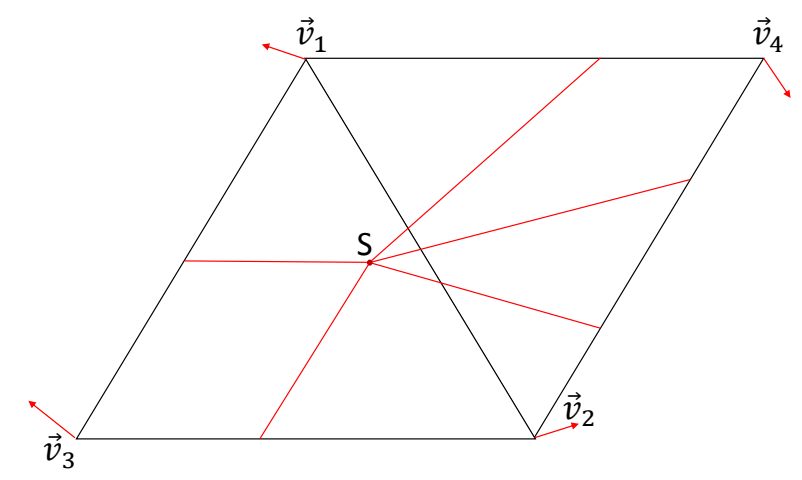

Figura 3.19: Utilizamos os dois triângulos que compartilham a aresta mais próxima da singularidade para calcular o início das separatrizes referentes à essa singularidade.

de integração descrito na Seção 3.3.

Também usamos o conceito de singularidades geométricas descrito na Seção 3.4. A Figura 3.20 mostra um exemplo de singularidade geométrica e como propomos gerar separatrizes a partir dela. O primeiro passo é detectar que esse vértice é um canto da fronteira: basta percorrer a fronteira, procurando duas arestas consecutivas que tenham um ângulo menor do que $\frac{3 \pi}{4}$ ou maior do que $\frac{5 \pi}{4}$. Esse vértice é então uma singularidade geométrica e tem sua direcionalidade correspondente (desenhada pelos vetores em preto e vermelho na Figura 3.20). Uma solução direta seria lançar uma separatriz na direção de cada um desses quatro vetores. Entretanto, como a singularidade está na fronteira, não é necessário lançar uma separatriz na direção da fronteira. Para evitar isso, eliminamos os vetores da direcionalidade que estão mais perto da direção da fronteira. Esses vetores estão pintados em preto na Figura 3.20. Naturalmente, também não traçamos separatrizes externas ao domínio. Os vetores que não foram eliminados serão usados para lançar uma separatriz, esses vetores estão pintados em vermelho na Figura 3.20. As separatrizes são criadas com o mesmo método de integração descrito na Seção 3.3, usando como direção inicial o vetor da direcionalidade correspondente.

\section{Combinação de separatrizes}

Como será discutido, analisamos o aumento do raio de influência visando diminuir o número final de regiões quadrilaterais da partição do domínio. Com isso, nosso algoritmo precisa combinar separatrizes discrepantes. 


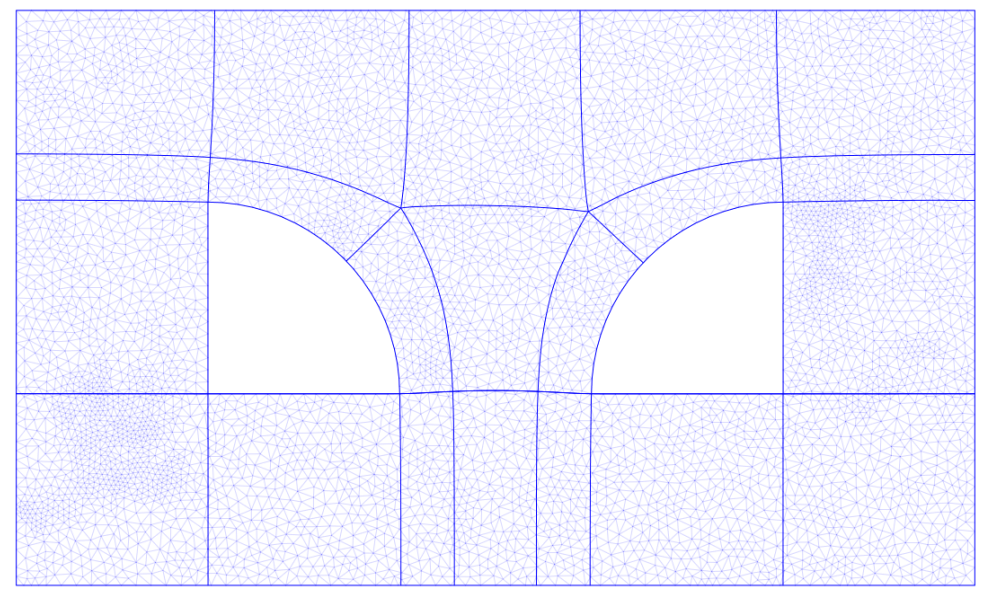

(a) Modelo com buracos.

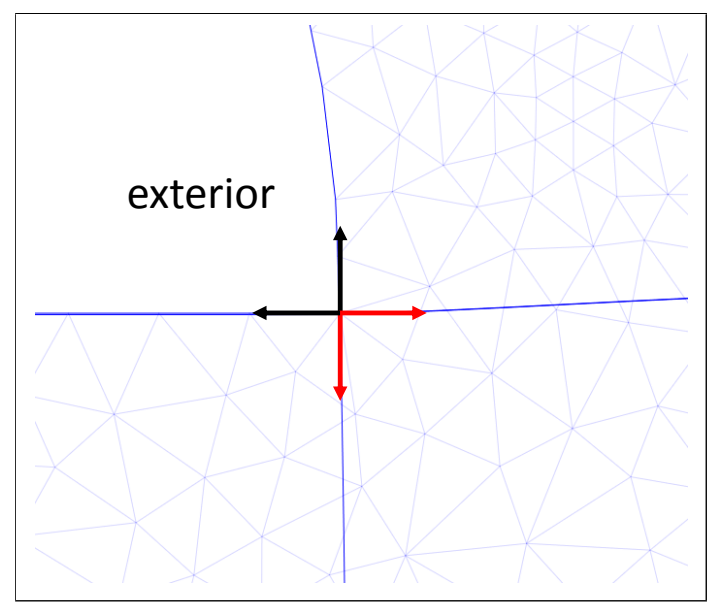

(b) Região referente ao modelo da Figura (a), exemplificando um caso de singularidade geométrica.

Figura 3.20: Exemplo de singularidade geométrica e suas separatrizes.

Para combinar as separatrizes que têm como extremidades os mesmos pontos de singularidade, usamos a mesma ideia da Seção 3.3.1. Entretanto, substituímos a interpolação linear pela interpolação cúbica de Hermite (13):

$$
\begin{aligned}
w_{0} & =2 t^{3}-3 t^{2}+1 \\
w_{1} & =1-w_{0} \\
\gamma(t) & =w_{0} \gamma_{1}(t)+w_{1} \gamma_{2}(1-t)
\end{aligned}
$$

Fizemos essa escolha pois precisamos combinar separatrizes que são muito discrepantes, devido ao aumento do raio de influência. Como queremos que a separatriz tenha precisão maior quanto mais perto ela está da singularidade que a originou, uma interpolação cúbica funciona melhor nesse caso. 


\section{Combinação de separatrizes não simétricas}

Existem casos em que é criada uma separatriz que tem início em uma singularidade e final em outra, mas a separatriz reversa não tem final nessa singularidade. Novamente, visando diminuir o número de regiões quadrilaterais resultantes optamos por combinar também essas separatrizes. Para fazer isso, realizamos os seguintes passos:

1. Temos a separatriz $\gamma_{1}$, que vai de $S_{0}$ até $S_{1}$.

2. Verificamos qual separatriz, $\gamma_{2}$, saindo de $S_{1}$ tem direção de saída mais próxima de $\gamma_{1}$.

3. Achamos o ponto $P$ de $\gamma_{2}$ mais perto de $S_{0}$ e usamos a Equação 3-11 para gerar a combinação das separatrizes com $\gamma_{1}$ de $S_{0}$ até $S_{1}$ e $\gamma_{2}$ de $S_{1}$ até $P$.

\subsection{4}

\section{Variação do raio de influência}

Nos próximos exemplos, vamos ilustrar como a variação do raio de influência altera o número de regiões quadrilaterais. Com esses exemplos, também é possível entender melhor a combinação de separatrizes.

Na Figura (a), exemplificamos um modelo com duas singularidades. Neste modelo as duas singularidades não se encontram com raio pequeno pois o domínio não é perfeitamente simétrico (o buraco da direita é maior que o da esquerda). Aumentando o raio de influência é possível atrair a separatriz $\gamma_{1}$ para uma singularidade. Com isso, $\gamma_{1}$ e $\gamma_{2}$ são separatrizes não simétricas. Ao combiná-las geramos $\gamma_{c}$, como mostra a Figura (b).

Na Figura 3.22, é mais claro que o domínio também não é simétrico. Entretanto, mesmo se aumentarmos bastante o raio, como na Figura (b), não conseguimos atrair uma separatriz para uma singularidade.

\section{5 .5}

\section{Partição de domínios com restrições}

Um dos objetivos desta dissertação é investigar a subdivisão de domínios complexos, como por exemplo domínio geológicos, que também tenham restrições em seu interior. Queremos decompor o domínio em regiões quadrilaterais de tal forma que as direcionalidades prescritas pelas restrições interiores não introduzam descontinuidades no campo. A Figura 3.23 ilustra um exemplo de 


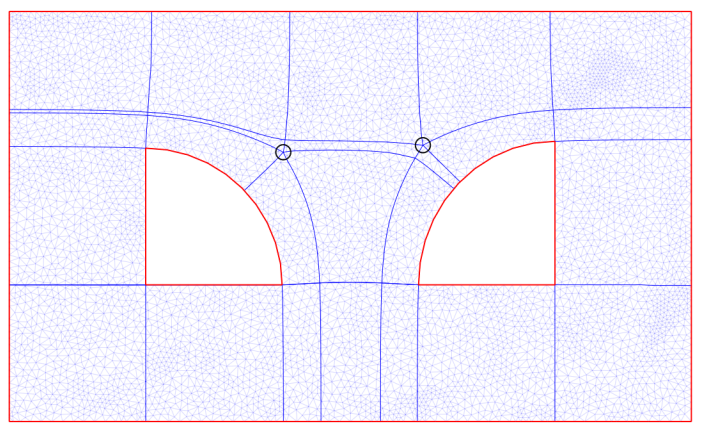

(a) Raio $=0.11$
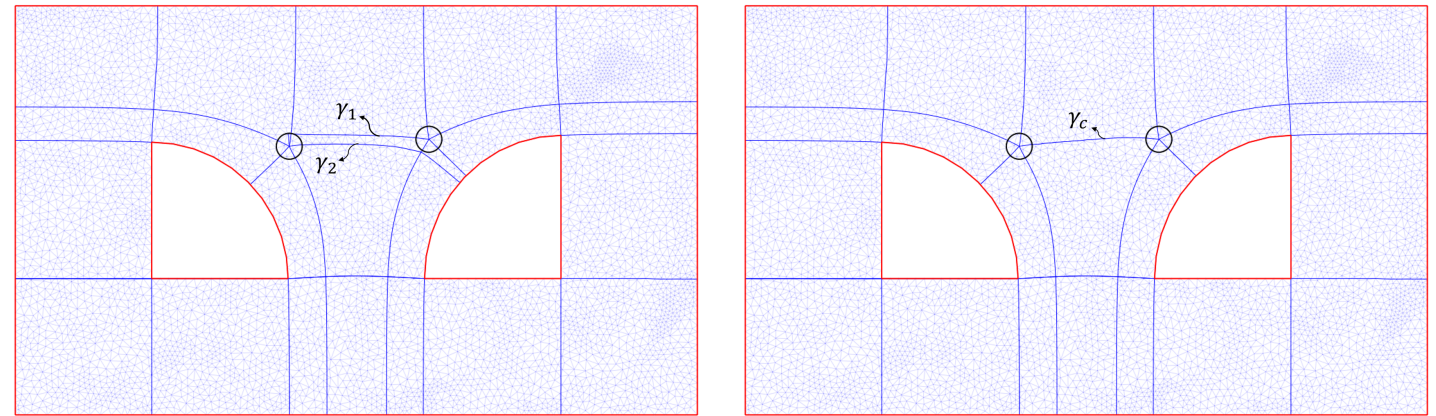

(b) Raio $=0.19$

Figura 3.21: Comparação entre diferentes raios no mesmo domínio.

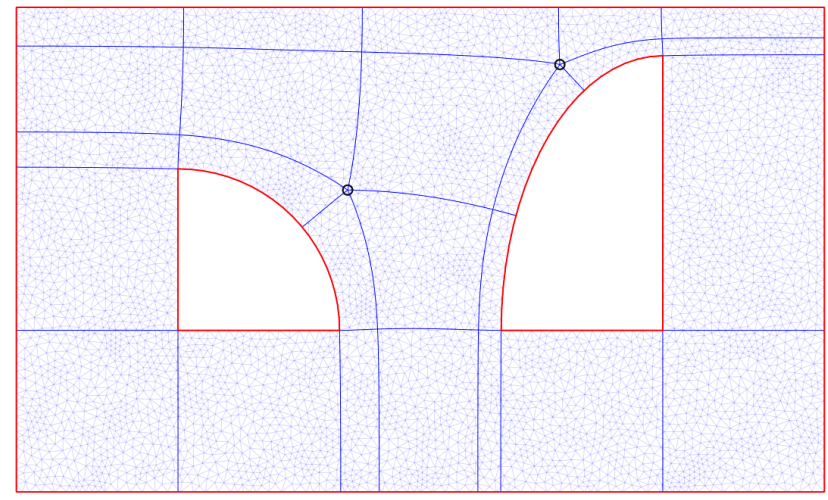

(a) Raio $=0.06$

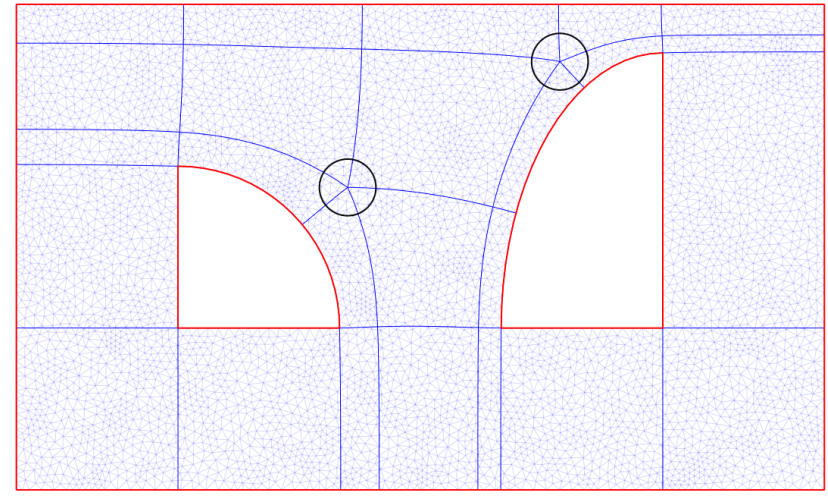

(b) Raio $=0.35$

Figura 3.22: Comparação entre diferentes raios no mesmo domínio. 


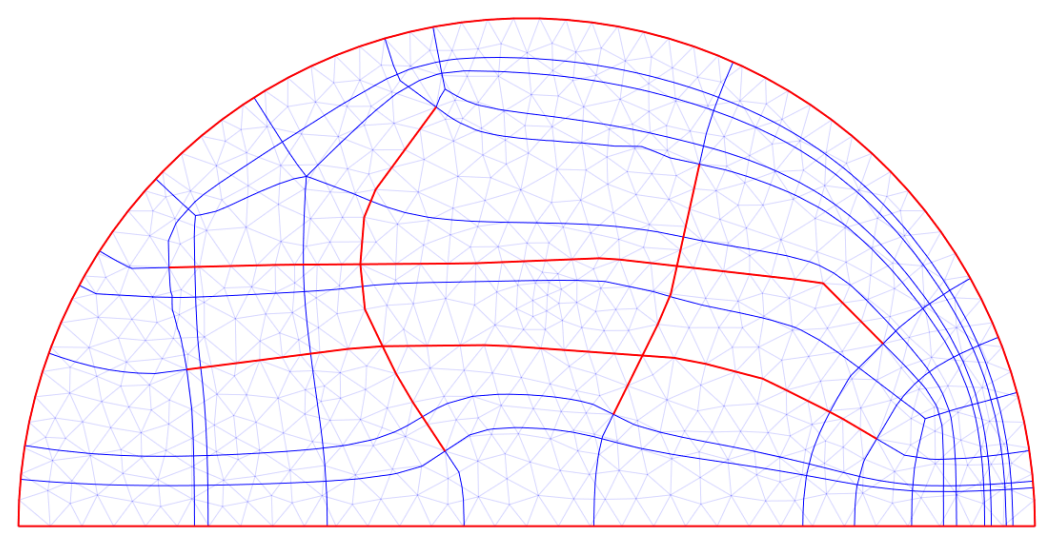

Figura 3.23: Domínio com restrição em seu interior e a subdivisão gerada.

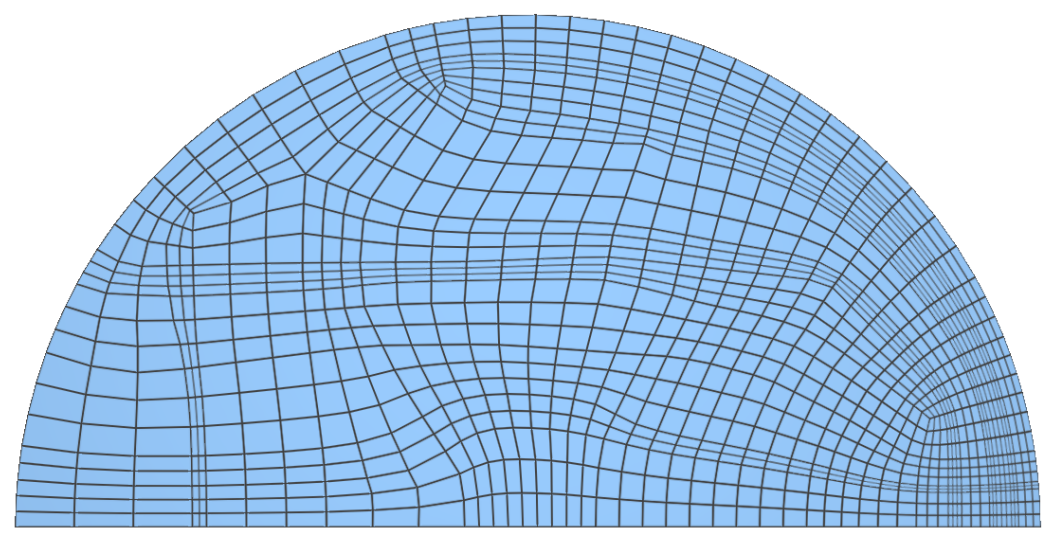

Figura 3.24: Malha de quadriláteros gerada a partir das regiões da Figura 3.23.

um domínio que possui restrições em seu interior (em vermelho) e as separatrizes (em azul). As restrições, junto com as separatrizes, formam as regiões quadrilaterais.

Para gerar as regiões quadrilaterais, tratamos as extremidades das restrições como singularidades geométricas. Isso significa que a partir de um ponto de extremidade, lançaremos três separatrizes pois não é necessário lançar uma separatriz na região da fronteira (restrição), como explica a Figura (b).

O resultado obtido mostra que as separatrizes lançadas a partir das singularidades geométricas acompanharam o campo de direcionalidade e assim foi possível subdividir o domínio em regiões quadrilaterais próprias para um mapeamento direto. A Figura 3.24 mostra um mapeamento possível. Essa malha foi gerada pelo programa Sigma2D (22), utilizado para modelagem e geração de malhas de elementos finitos.

O modelo da Figura 3.23 não é um modelo real. Como investigação futura, queremos usar modelos geológicos reais como o trabalho de Araújo e Celes (1). A Figura 3.25 mostra um exemplo de um domínio geológico. 


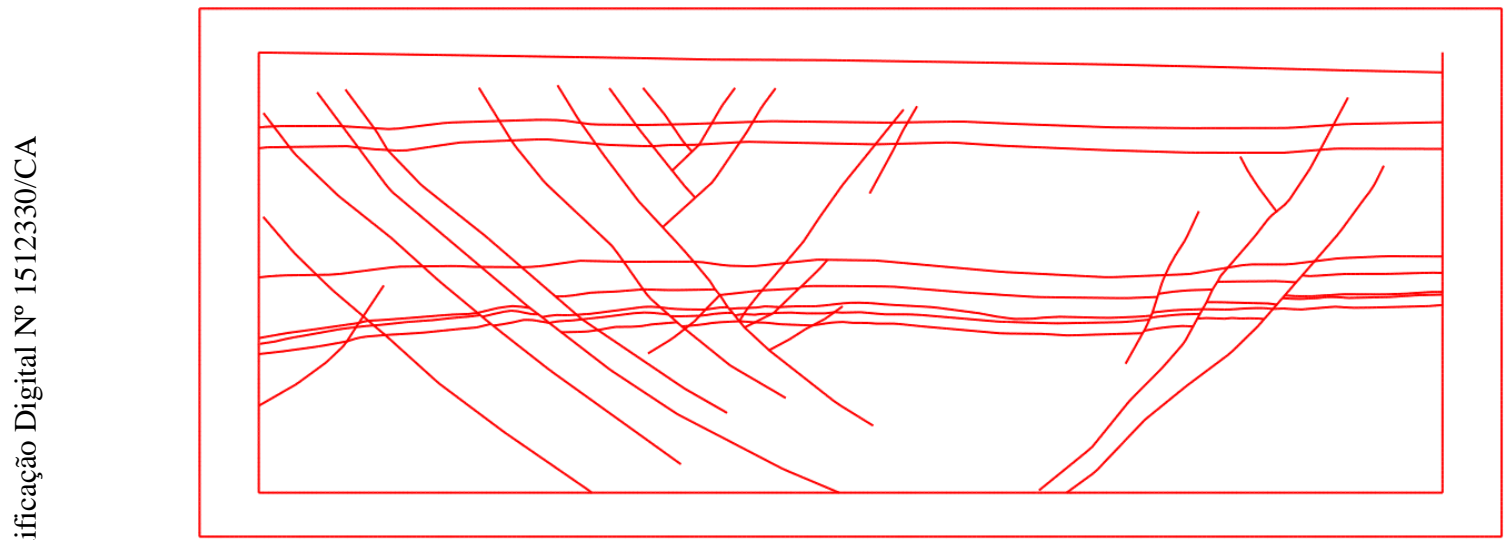

Figura 3.25: Domínio geológico. 


\section{Métrica de qualidade de alinhamento de malhas quadrilaterais}

Uma aplicação possível para a direcionalidade é usá-la para medir o alinhamento de malhas quadrilaterais e, consequentemente, a qualidade dessas malhas. Como mencionado no Capítulo 2, não existe uma métrica que analise a qualidade de alinhamento de malhas de quadriláteros. Como segunda etapa deste trabalho, propomos uma métrica para avaliar o alinhamento de malhas quadrilaterais, dividida nas seguintes etapas, ilustradas na Figura 4.1:

a: Entrada: Malha de quadriláteros $Q$ do domínio $\Omega$ e suas restrições

b: Malha de triângulos $T$ criada a partir de $Q$

c: Campo de direcionalidade de $\Omega$

d: Saída: Métrica de qualidade de alinhamento

Dada uma malha de quadriláteros $Q$ (Figura (a)), a primeira etapa é gerar uma malha de triângulos $T$ (Figura (b)) a partir de $Q$. Para isso, realizamos

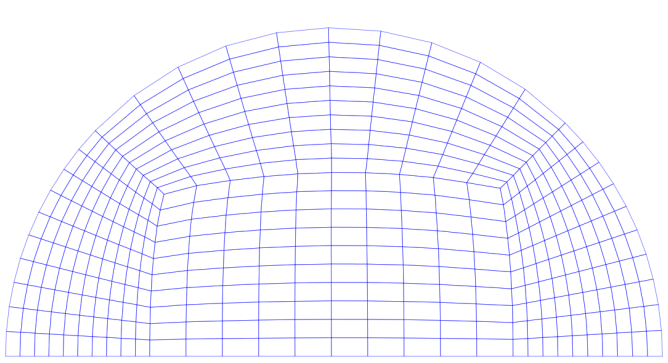

(a) Malha de quadriláteros.

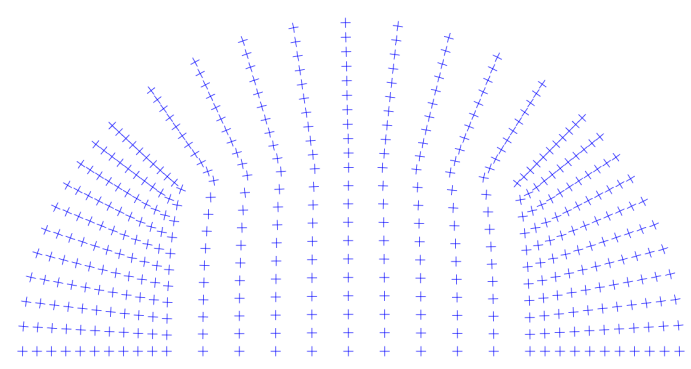

(c) Campo de direcionalidade.

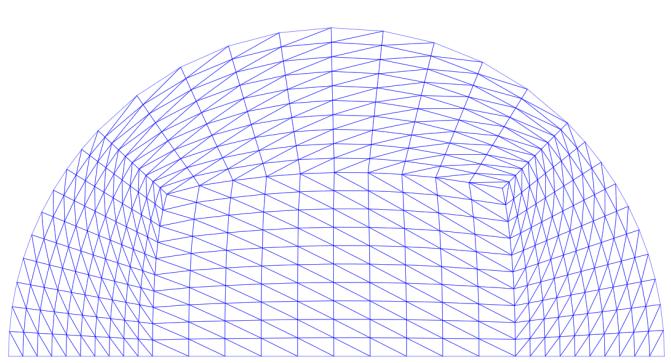

(b) Malha de triângulos.

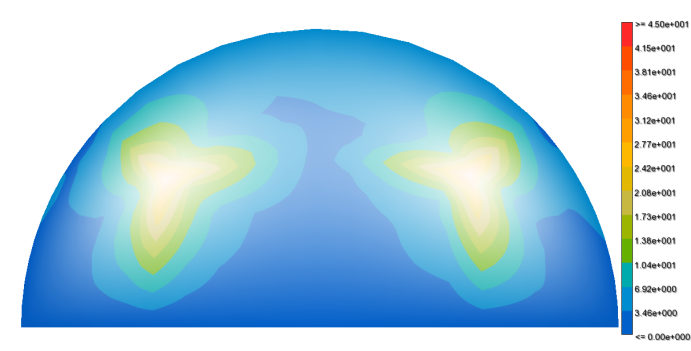

(d) Qualidade de alinhamento.

Figura 4.1: Etapas da geração da métrica de qualidade de alinhamento de malhas quadrilaterais. 
o procedimento simples de subdividir cada quadrilátero em dois triângulos usando uma de suas diagonais. A partir da malha de triângulos $T$, o próximo passo é gerar o campo de direcionalidade (Figura (c)) do domínio. Para isso, usamos o método de difusão da Seção 3.5.1, em que propagamos as informações das restrições para todo o domínio. A partir da direcionalidade em cada vértice, avaliamos a qualidade da forma descrita a seguir.

A métrica é composta por dois fatores: desvio $d$ e confiabilidade $\alpha$. A métrica analisa cada vértice: cada vértice $i$ terá o seu desvio $d_{i}$ e sua confiabilidade $\alpha_{i}$ correspondente.

O desvio representa o quão desalinhado está o vértice em relação à sua direcionalidade. Para essa avaliação, comparamos cada aresta incidente ao vértice com os vetores $\vec{v}_{k}$ da sua direcionalidade. Para cada aresta $e_{i}$, achamos qual $\vec{v}_{k}$ faz o menor ângulo $\left(\theta_{\min _{i}}\right)$ com $e_{i}$. O desvio será o maior $\theta_{\text {min }_{i}}$ :

$$
d=\max \left\{\theta_{\min _{i}}\right\}
$$

A Figura 4.2 ilustra o desvio, mostrando qual aresta (azul) e qual $\vec{v}_{k}$ (vermelho) compõem $d$. As regiões mais alinhadas são as regiões em que a direcionalidade sobrepõe as arestas e as regiões mais desalinhadas são as regiões em que a direcionalidade faz $45^{\circ} \mathrm{com}$ as arestas.

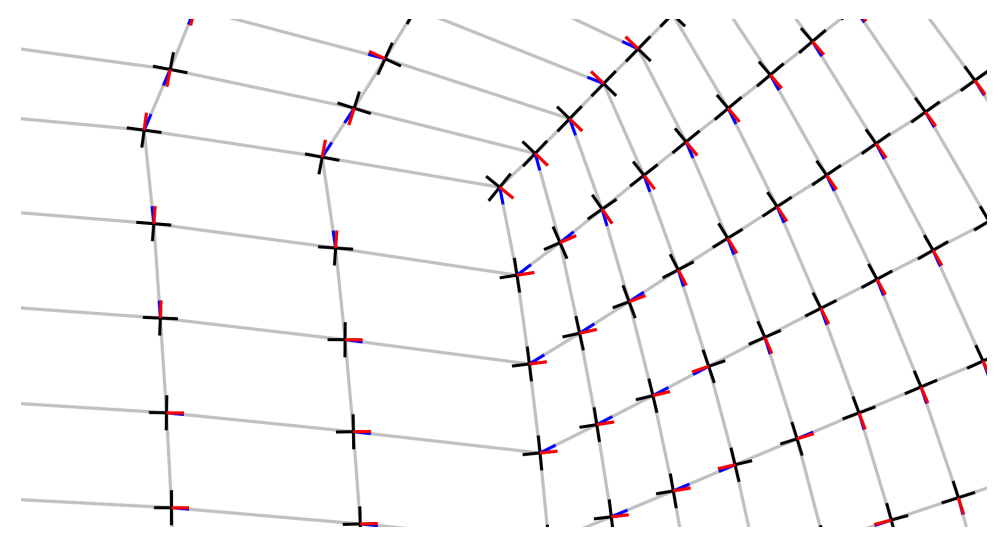

Figura 4.2: Representação do desvio. As arestas da malha de quadriláteros estão representadas em cinza e a direcionalidade em preto. Os vetores azuis e vermelhos são os que usamos para calcular o ângulo entre uma aresta (azul) e o vetor da direcionalidade (vermelho) do vértice mais próximo dessa aresta.

A confiabilidade $\alpha$ está relacionada a quão confiável é a medida do desvio em cada vértice. Sabemos que a direcionalidade é indefinida nas singularidades e que é prescrita nas restrições. Isso significa que não temos como avaliar o alinhamento nas singularidades, pois não temos a informação da direcionalidade nesse ponto. Por outro lado, nas restrições, a medida de direcionalidade é completamente confiável, pois a mesma é prescrita. Então podemos dizer que a confiabilidade nas singularidades é 0 e que a confiabilidade nas restrições 
é 1. Esses valores são coerentes com a magnitude (Figura 4.3) do vetor de representação da direcionalidade, então podemos usá-la como valor de $\alpha$ :

$$
\alpha=\left\|\vec{v}_{r}\right\|
$$

Para a visualização da métrica, propomos a composição $d$ e $\alpha$, em que $d$ representa a cor de cada vértice e $\alpha$ a transparência da cor, como ilustrado na Figura 4.4. Assim, quanto menor o desvio, mais perto de azul e quanto maior o desvio, mais perto de vermelho. Observando a Figura 4.3 junto com a Figura 4.4, vemos que a maior transparência está nas áreas próximas às singularidades.

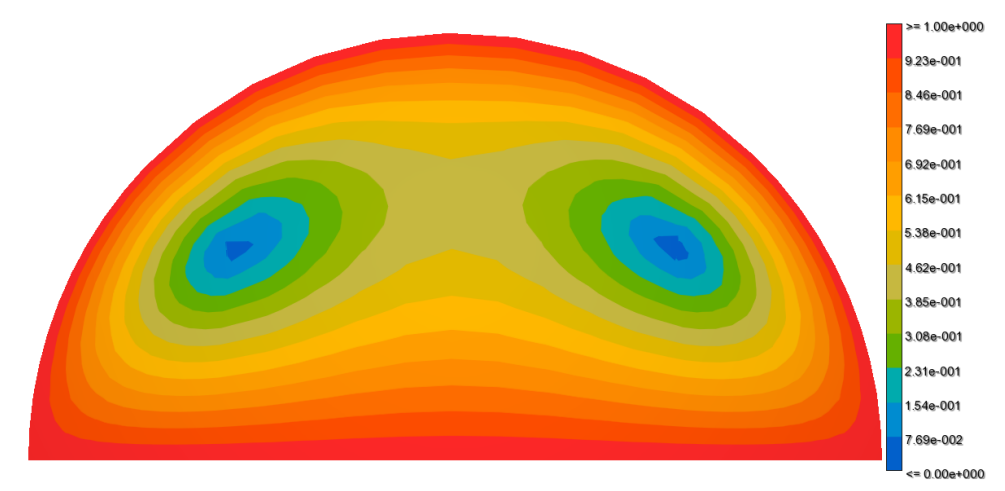

Figura 4.3: Magnitude $(\alpha)$ do campo do vetor de representação da direcionalidade.

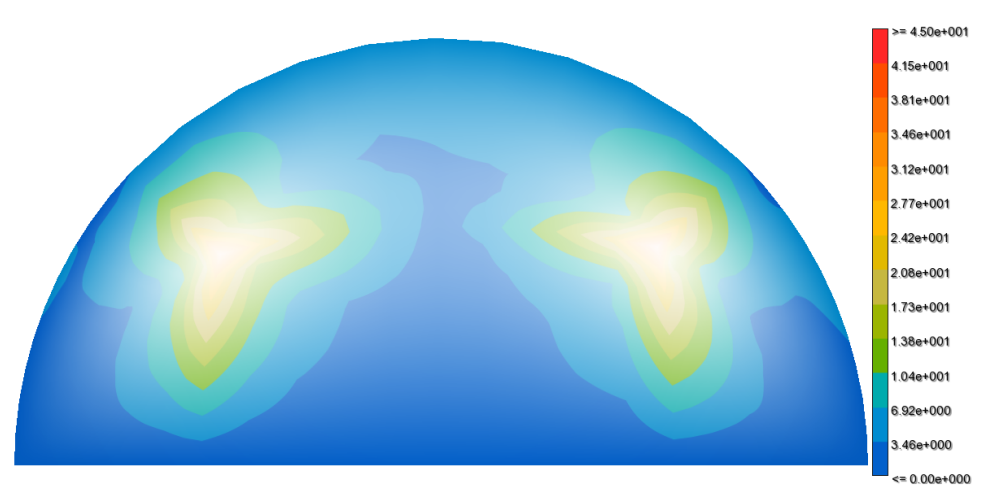

Figura 4.4: Métrica de qualidade de alinhamento, em o desvio $(d)$ representa a cor de cada vértice e a confiabilidade $(\alpha)$ a transparência da cor.

Para analisar graficamente a métrica de qualidade de uma malha, propomos o uso de um gráfico de barras resultante da composição de diferentes histogramas. Cada histograma apresenta a distribuição do desvio $d$ considerando apenas vértices que têm confiabilidade $\alpha$ dentro de um dado intervalo. Nos gráficos plotados neste texto, optamos por usar cinco intervalos. Assim, o primeiro intervalo, mais confiável, considera a distribuição do desvio de vértices 


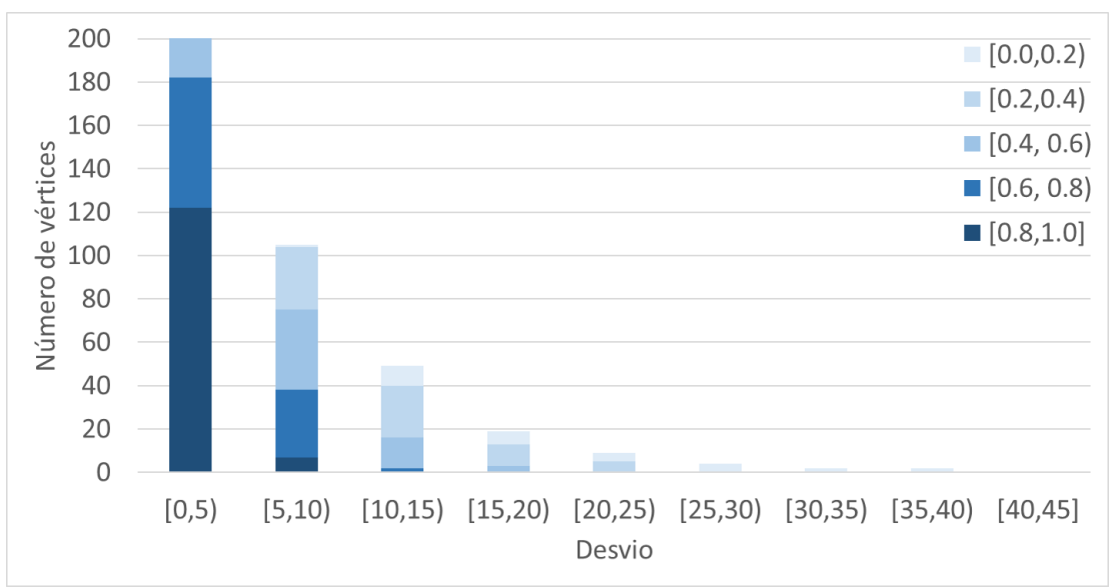

Figura 4.5: Gráfico do desvio quantizado em intervalos de $\alpha$.

com confiabilidade no intervalo $[0.8,1.0]$. Para este intervalo, usamos uma cor mais opaca no gráfico. Para os demais intervalos, $[0.6,0.8),[0.4,0.6),[0.2,0.4)$ e $[0.0,0.2)$, usamos cores menos opacas, compondo o gráfico de barras ilustrado na Figura 4.5 para o modelo em questão. Note como o gráfico revela a boa qualidade dessa malha. Os menores desvios (boa qualidade) são na grande maioria valores confiáveis, enquanto que os maiores desvios (baixa qualidade) ocorrem em regiões de baixa confiabilidade, isto é, próximas às áreas de singularidade, onde a direcionalidade é indefinida.

Para facilitar a análise da qualidade de uma malha, em especial, para facilitar a comparação de qualidade entre malhas distintas, propomos também uma forma de condensar as informações do gráfico de barra composto em um gráfico de barra simples. O objetivo é criar uma ferramenta de análise baseada em valores simples, mas que ainda represente a distribuição do desvio considerando a confiabilidade. Para tanto, propomos um gráfico de barra que represente um "histograma de frequência" simples dos desvios, onde as ocorrências são ponderadas pelas confiabilidades. Obtemos então um gráfico de barras onde o tamanho de cada barra é dado pelo somatório dos valores de confiabilidade dos desvios. A Figura 4.6 ilustra o gráfico obtido para o mesmo modelo. Note como ele condensa de forma adequada as informações do gráfico composto, permitindo uma avaliação da distribuição da qualidade da malha. 


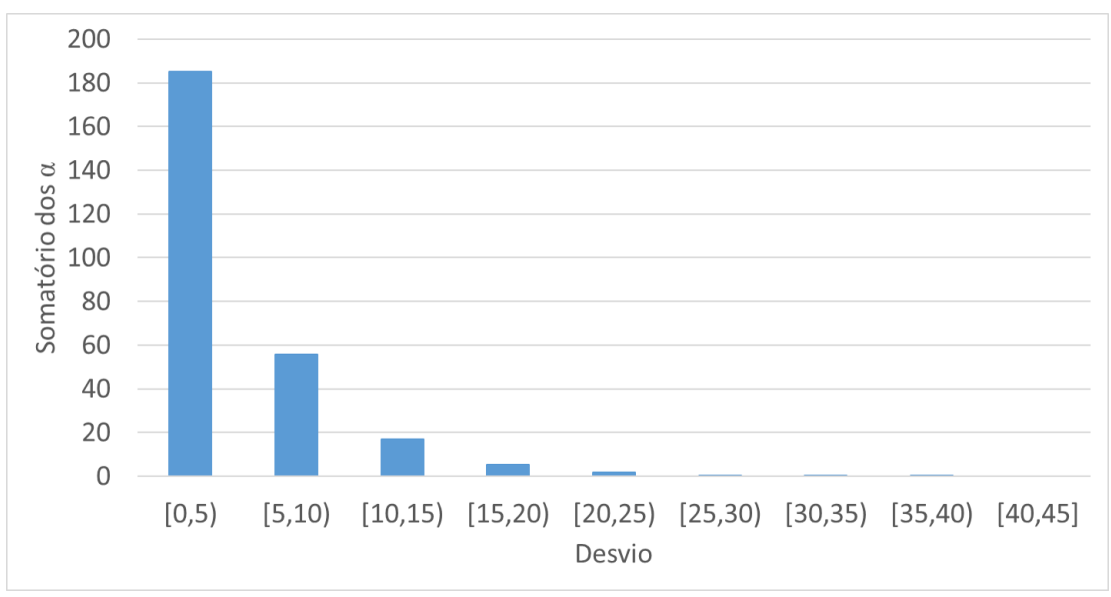

Figura 4.6: Gráfico de barras condensado, onde a altura de cada barra é ponderada pelo $\alpha$.

\section{1}

\section{Exemplos}

A seguir mostraremos alguns exemplos de malhas de quadriláteros e o resultado da métrica de qualidade de alinhamento para essas malhas.

\subsection{1}

\section{Influência do raio na qualidade da malha}

O Modelo 1 (Figura (a)) é um modelo totalmente simétrico e o Modelo 2 é uma variação não-simétrica do Modelo 1 , em que o buraco direito é maior do que o esquerdo. Para o Modelo 2 temos dois exemplos, o Modelo 2.1 (Figura (b)) representa a malha gerada pelas partições da Figura (a) em que não ocorre a combinação de separatrizes. O Modelo 2.2 (Figura (c)) representa a malha gerada pelas partições da Figura (b), após o aumento do raio de influência e combinação de separatrizes.

A Figura 4.8 mostra a magnitude dos vetores de representação dos Modelos 1 e 2. Ao comparar, é possível perceber como a não-simetria do modelo afeta a localização das singularidades. Vemos a métrica de qualidade na Figura 4.9. O Modelo 1 é o que possui maior área com menor desvio, seguido pelo Modelo 2.1 e por último o Modelo 2.2 que possui mais áreas com maior desvio. Note que a visualização proposta revela o espraiamento do desvio ao aumentarmos o raio de influência das singularidades. De fato, ao diminuirmos o número de partições do domínio, tendemos a aumentar o desvio.

Os gráficos de barra composto (Figura 4.10) mostram que o Modelo 2.2 tem menos vértices com menor desvio quando comparado com o número de vértices do Modelo 2.1. Entretanto, os três modelos têm qualidade muito boa pois a maioria dos vértices tem desvio pequeno. 


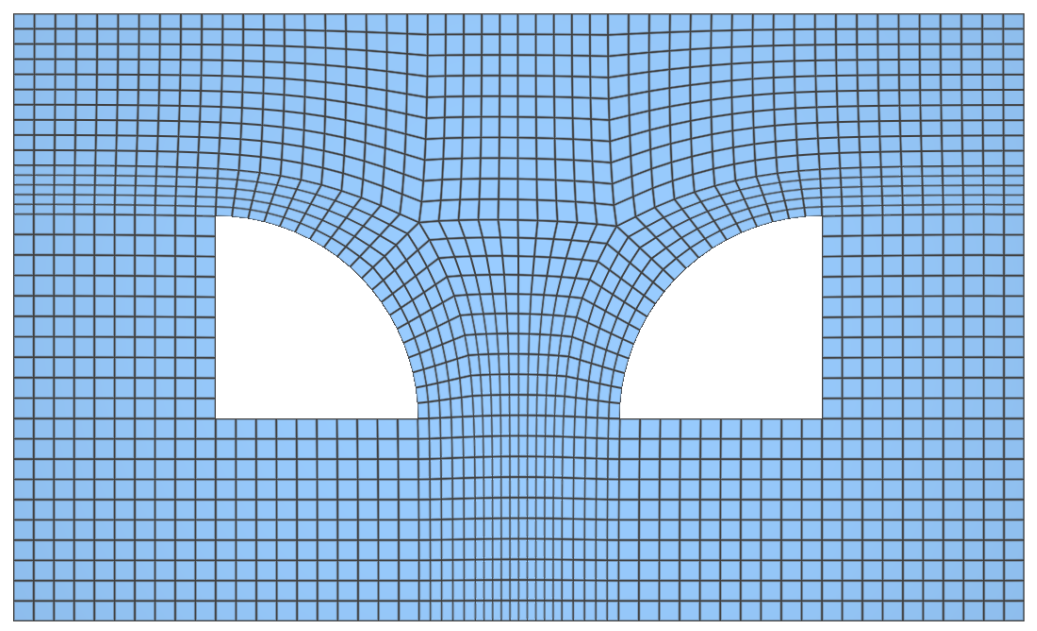

(a) Modelo 1: modelo simétrico.

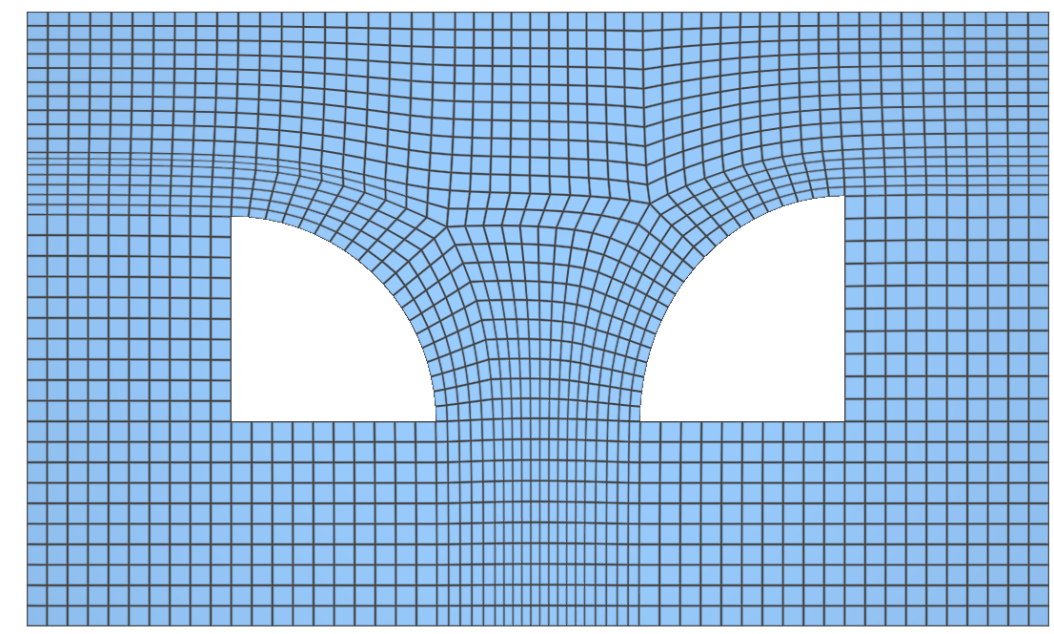

(b) Modelo 2.1: Modelo 2 sem o aumento do raio de influência.

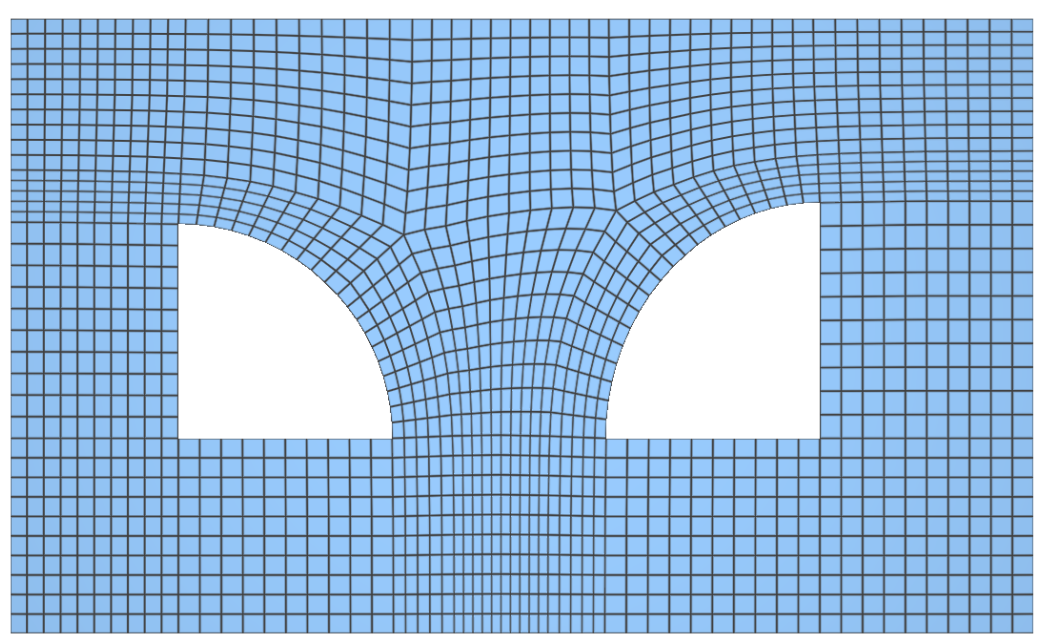

(c) Modelo 2.2: Modelo 2 com aumento de raio e combinação de separatrizes.

Figura 4.7: Modelos 1 e 2. 


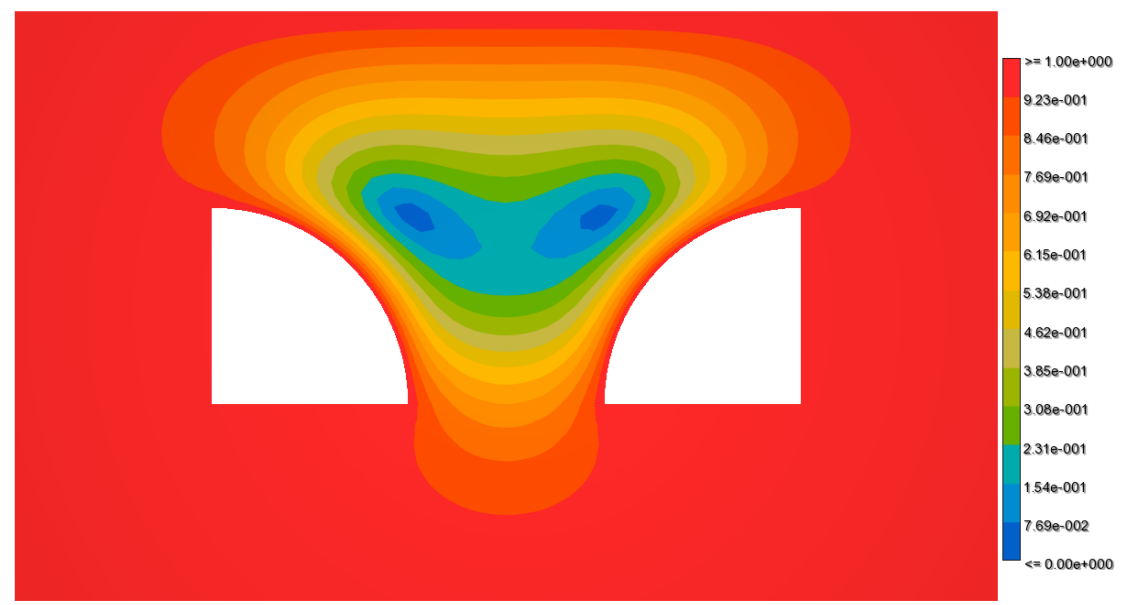

(a) Magnitude do campo do vetor de representação da direcionalidade do Modelo 1.

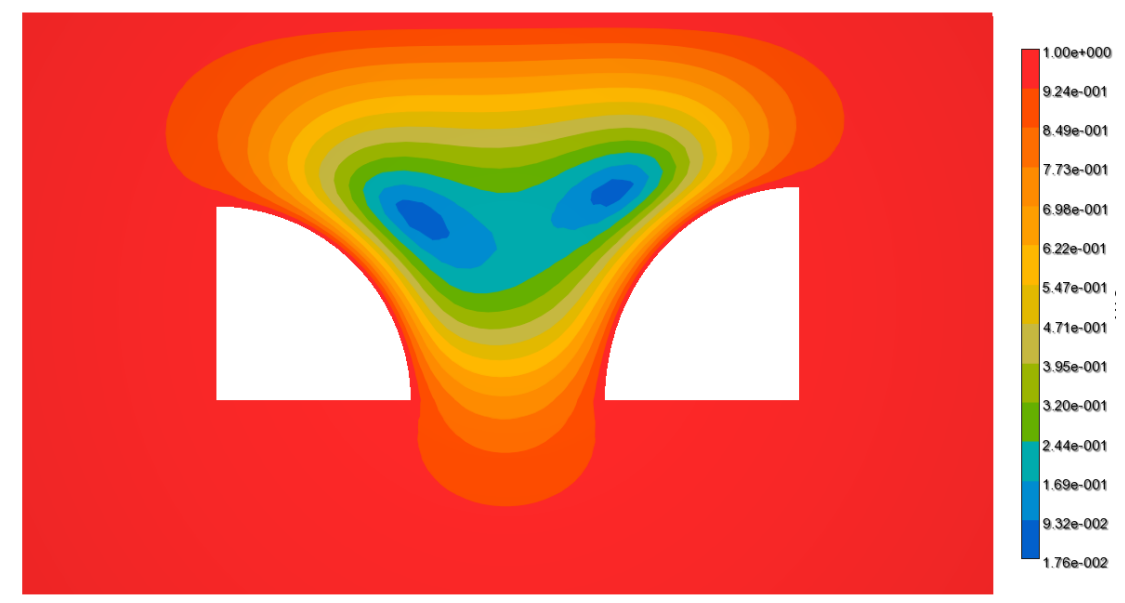

(b) Magnitude do campo do vetor de representação da direcionalidade do Modelo 2.

Figura 4.8: Magnitude do campo do vetor de representação da direcionalidade.

Os modelos não têm o mesmo número de vértices, então não podemos comparar os tamanhos das barras nos gráficos da Figura 4.11, apenas suas distribuições. O gráfico do Modelo 2.2 (Figura (c)) está ligeiramente pior distruibuído do que o do Modelo 2.1 (Figura (c)). Isso faz sentido, pois quando aumentamos o raio estamos ignorando o campo de direcionalidade, isso gera um pequeno desalinhamento. 


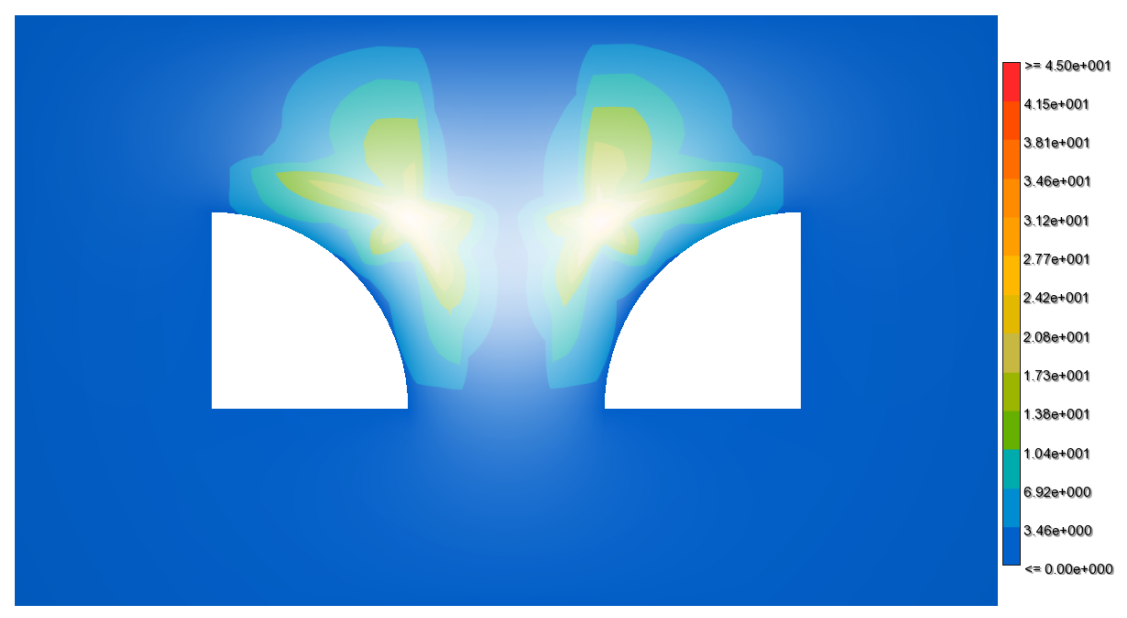

(a) Métrica de qualidade de alinhamento para o Modelo 1.

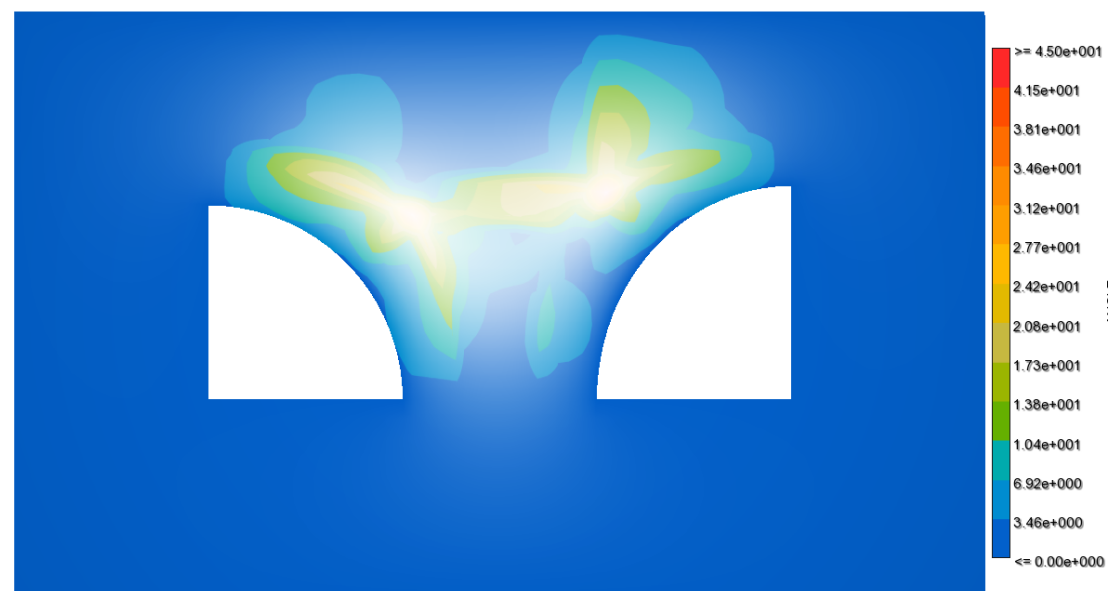

(b) Métrica de qualidade de alinhamento para o Modelo 2.1.

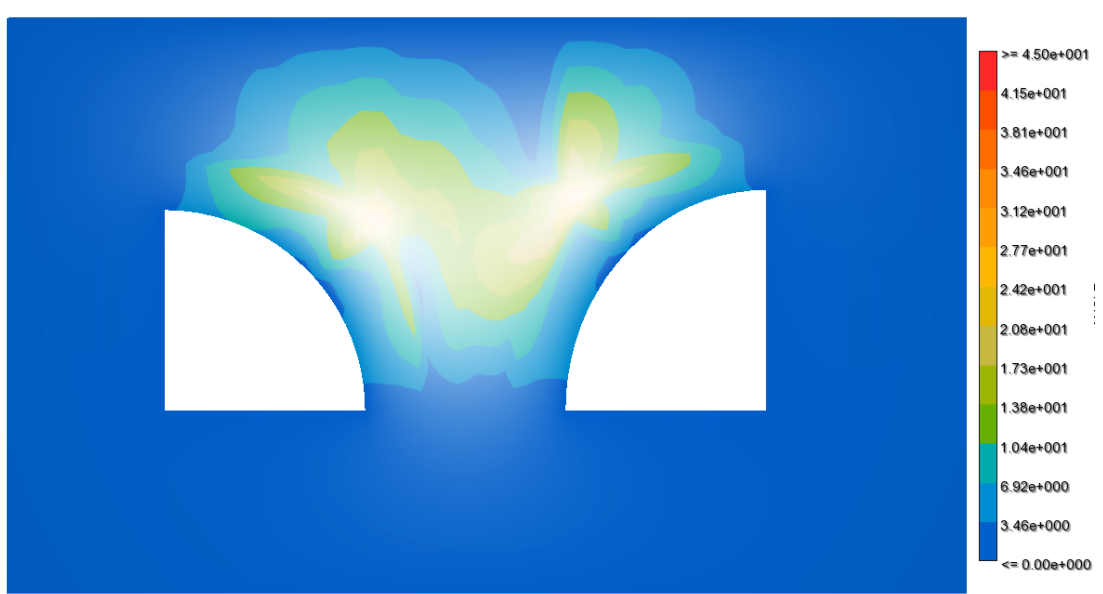

(c) Métrica de qualidade de alinhamento para o Modelo 2.2.

Figura 4.9: Métrica de qualidade de alinhamento. 


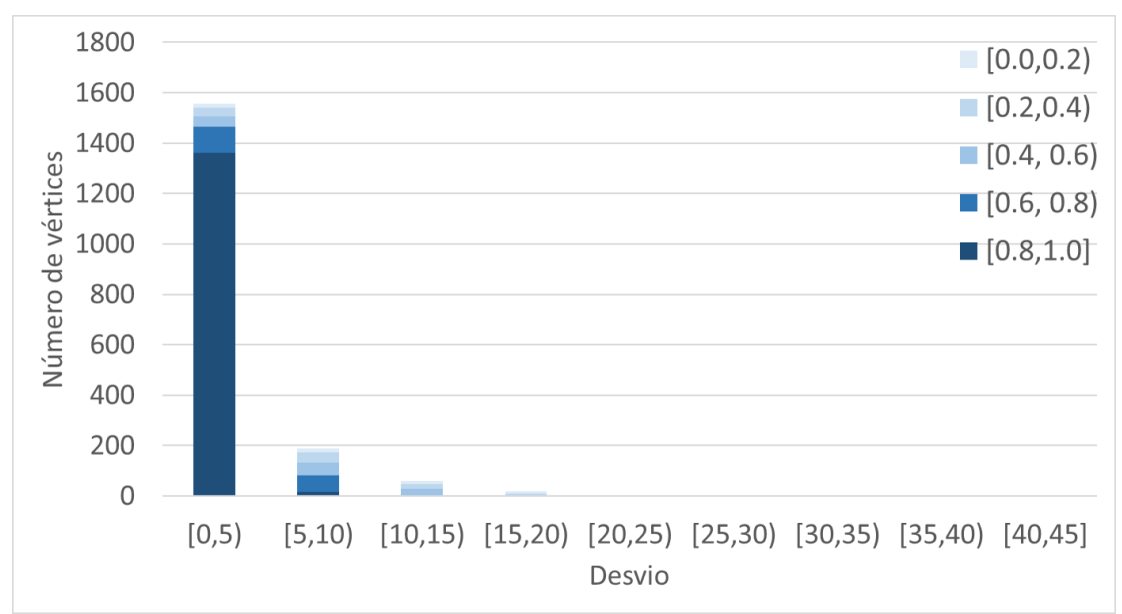

(a) Gráfico de barras referente ao Modelo 1.

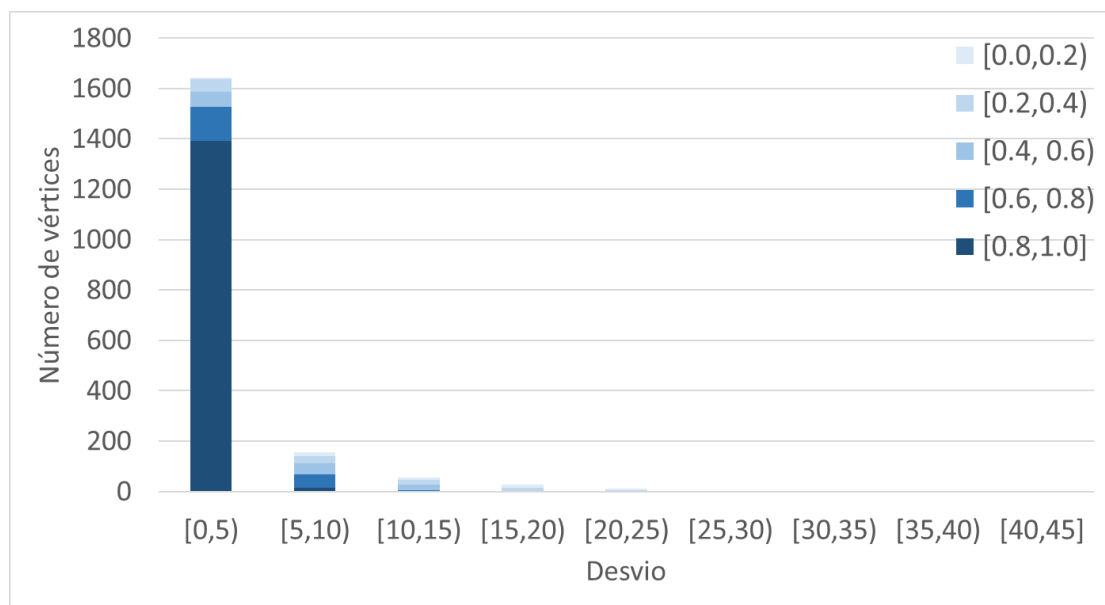

(b) Gráfico de barras referente ao Modelo 2.1.

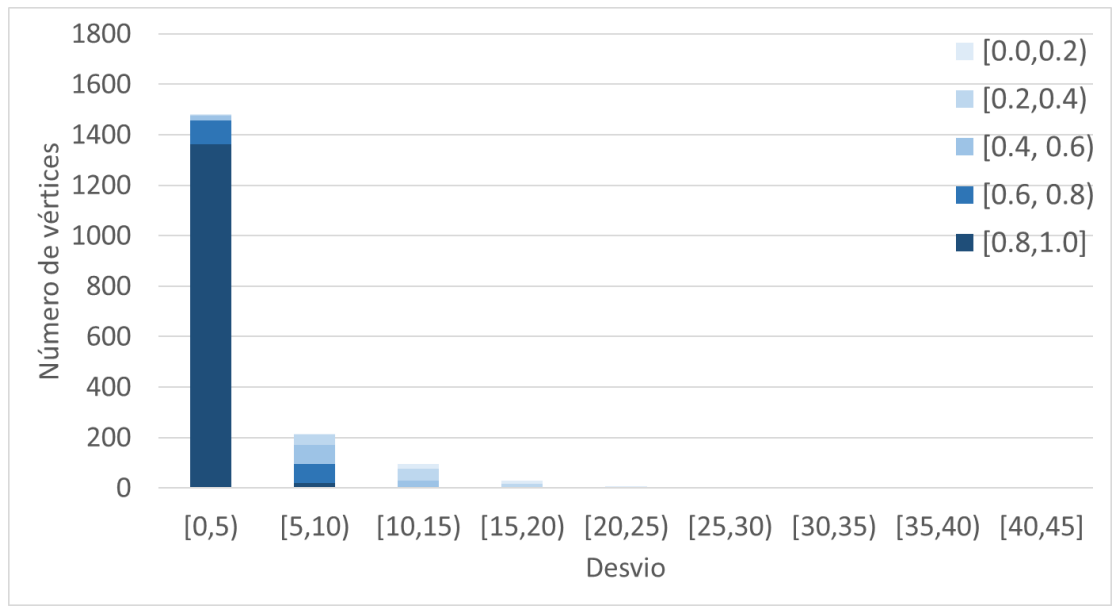

(c) Gráfico de barras referente ao Modelo 2.2.

Figura 4.10: Gráfico do desvio quantizado em intervalos de $\alpha$. 


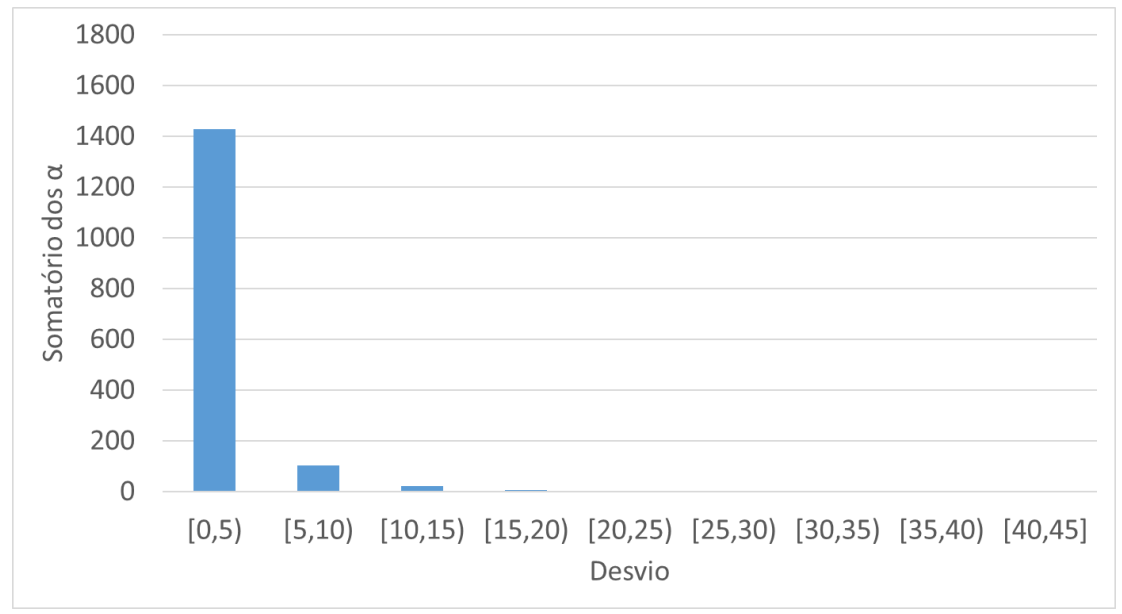

(a) Gráfico de barras referente ao Modelo 1.

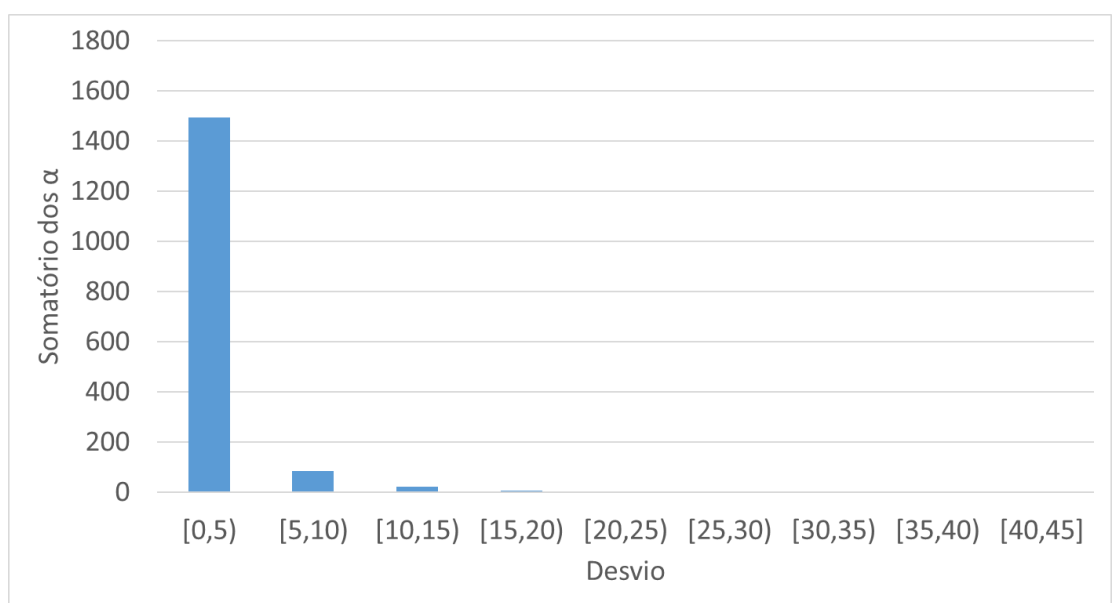

(b) Gráfico de barras referente ao Modelo 2.1.

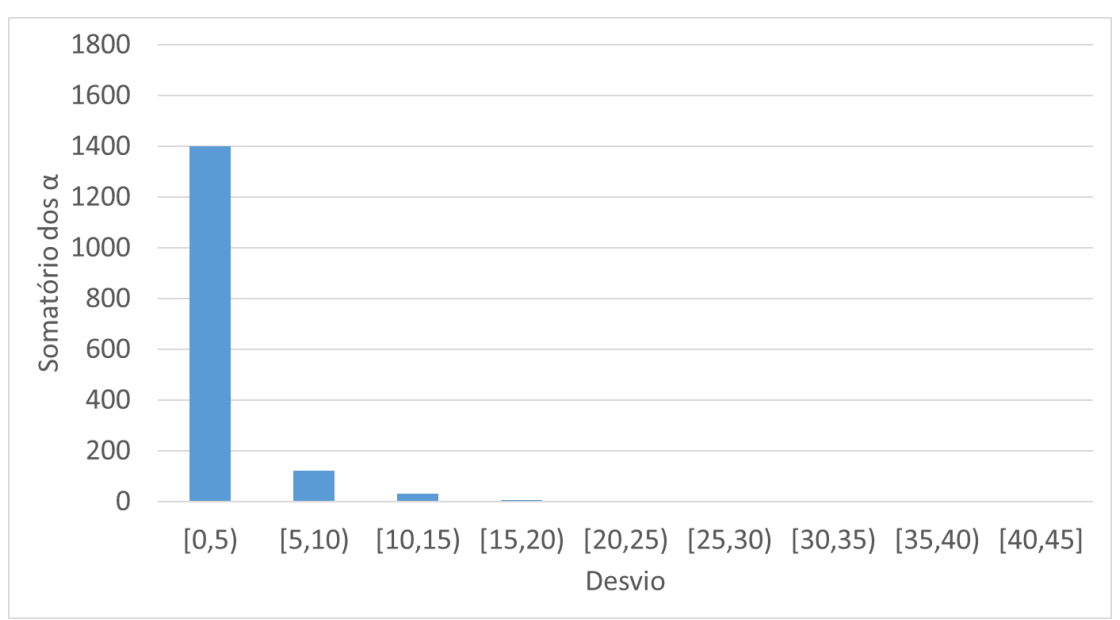

(c) Gráfico de barras referente ao Modelo 2.2.

Figura 4.11: Gráfico de barras condensado. 


\subsection{2}

\section{Domínios com restrições}

O Modelo 3 é um modelo com restrição em seu interior referente à Seção 3.5.5, em que geramos uma malha de quadriláteros (Figura (b)) através de um mapeamento direto das regiões quadrilaterais geradas pelo método de Kowalski et al. (9) (Figura (a)). O campo da magnitude dos vetores de representação da direcionalidade está ilustrado na Figura 4.13. A métrica de qualidade está ilustrada pela Figura 4.14 e em seguida temos os dois gráficos (Figuras 4.15 e 4.16 ).

Analisando os gráficos e a Figura 4.14, podemos dizer que a malha do modelo Modelo 3 possui uma boa qualidade de alinhamento, tendo a maior parte dos seus vértices na barra de menor desvio. Esse resultado mostra que o método da Seção 3.5.5 é capaz de gerar regiões quadrilaterais que possibilitam a geração de malhas de quadriláteros com boa qualidade.

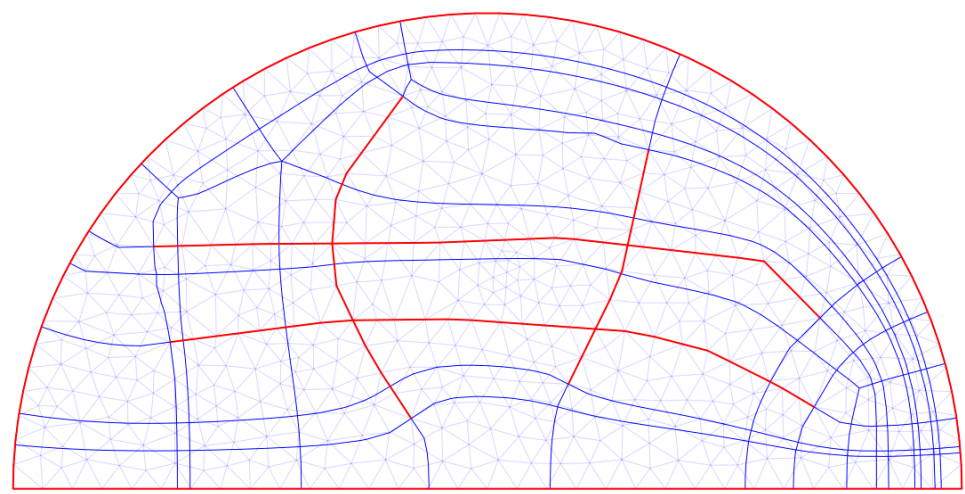

(a) Regiões quadrilaterais geradas pela partição de domínio, explicada na Seção 3.5.5. As restrições estão representadas em vermelho.

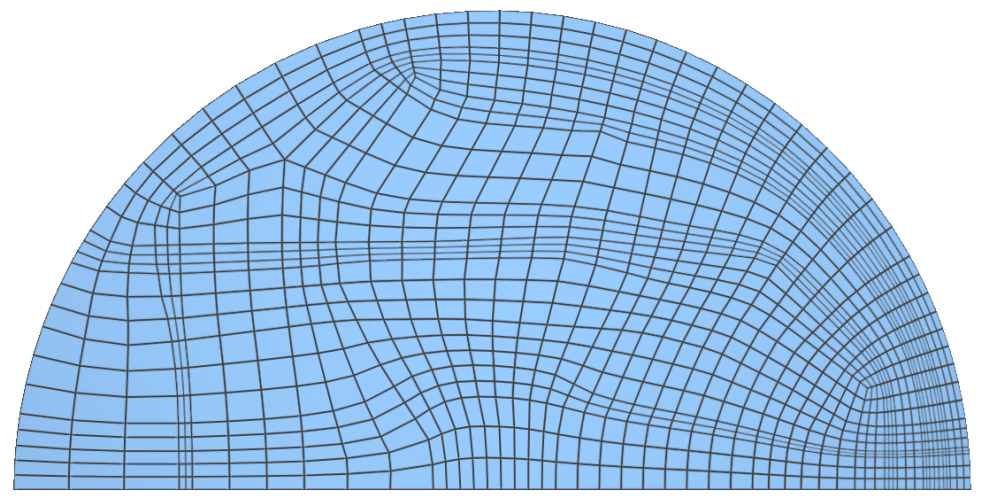

(b) Malha de quadriláteros gerada por um mapeamento direto das regiões, utilizando o Sigma (22).

Figura 4.12: Modelo 3. 


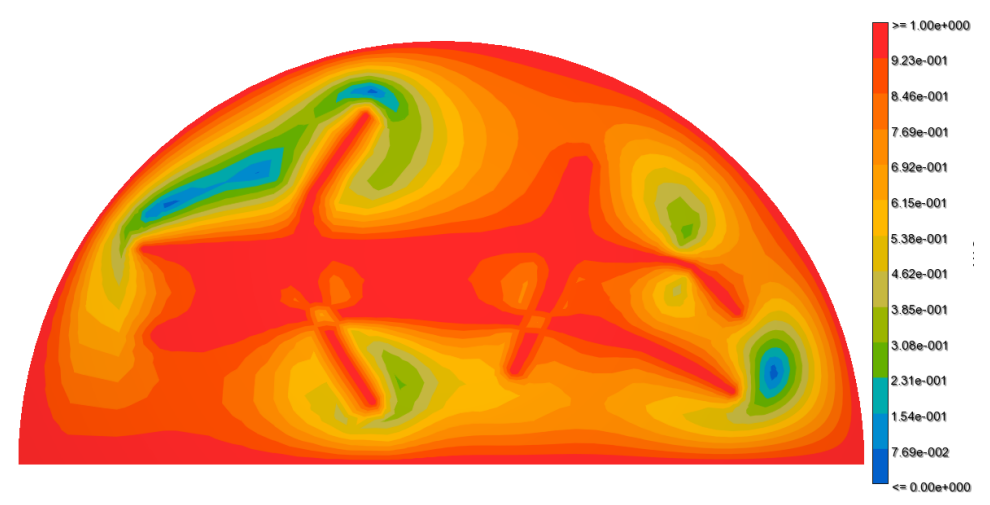

Figura 4.13: Magnitude do campo do vetor de representação da direcionalidade do Modelo 3.

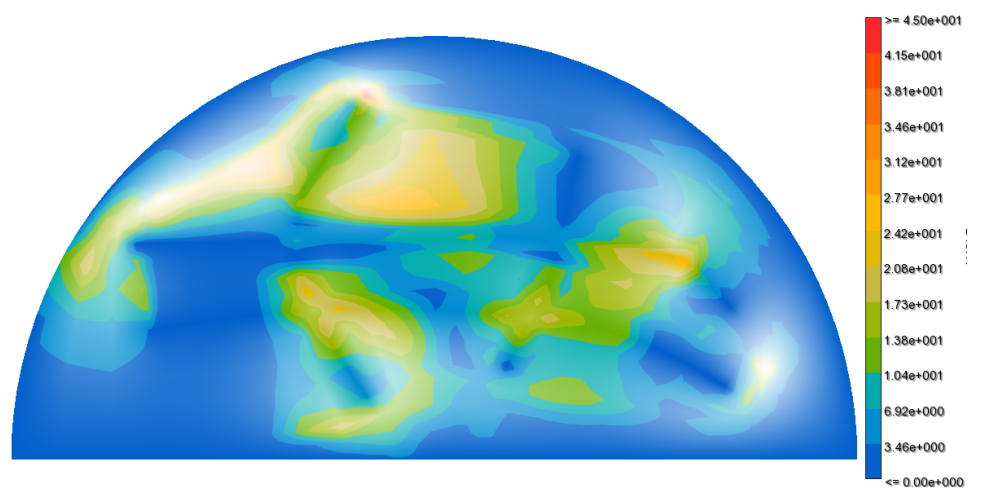

Figura 4.14: Métrica de qualidade de alinhamento para o Modelo 3.

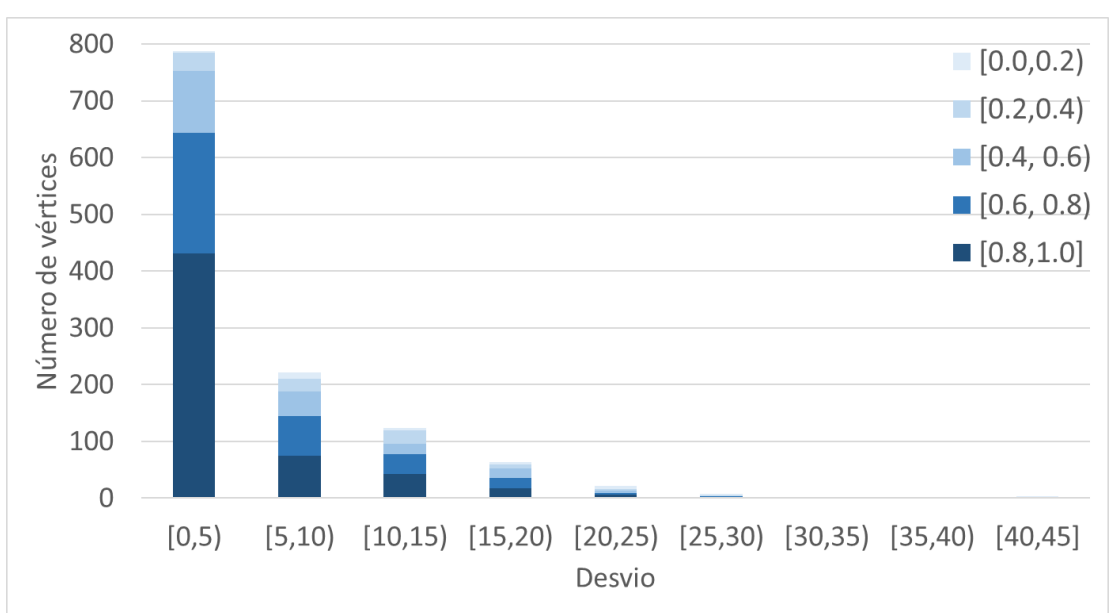

Figura 4.15: Gráfico do desvio quantizado em intervalos de $\alpha$.

O Modelo 4 é um modelo geológico que contém restrições prescritas em seu interior. Na Figura 4.17 vemos a malha de quadriláteros do Modelo 4, obtido pelo algoritmo proposto por Araújo e Celes (1) e suas restrições em vermelho. O campo da magnitude dos vetores de representação da direcionalidade está ilustrado na Figura 4.18, mostrando com clareza as áreas das singularidades em azul. A métrica de qualidade está ilustrada pela Figura 4.19, em seguida os 


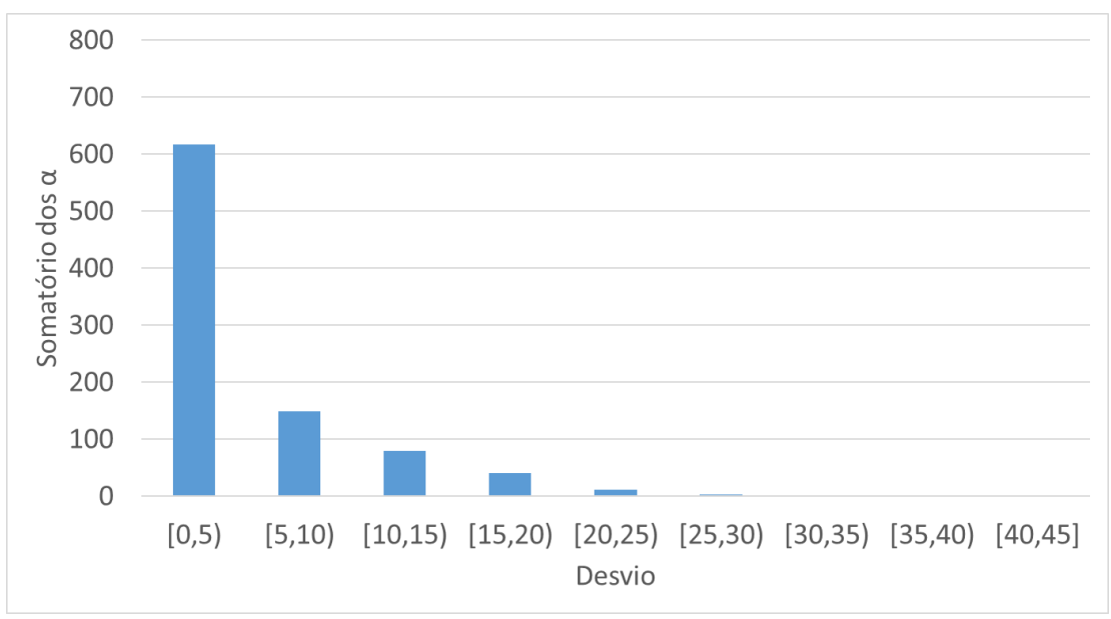

Figura 4.16: Gráfico de barras condensado.

dois gráficos (Figuras 4.20 e 4.21).

O método proposto por Araújo e Celes (1) utiliza uma malha inicial que é ajustada conforme restrições são inseridas. Com isso, a malha final tende ao alinhamento da malha inicial.

Na Figura 4.22, ilustramos uma área em detalhes. Na Figura (a), vemos a direcionalidade em cada vértice e as restrições prescritas em vermelho. Na Figura (b), a escala de cores representa o ângulo $\theta$ da qualidade. Note que, na região ilustrada, as restrições forçam um alinhamento da malha de $45^{\circ} \mathrm{em}$ relação aos eixos cartesianos. Como o método parte da malha inicial cartesiana, a região apresenta uma malha de boa qualidade de forma mas com alinhamento ruim. Qualquer métrica de malha de qualidade que analisa os elementos de forma isolada, iria indicar uma região de boa qualidade. Nossa métrica indica o desalinhamento.

Esta análise de qualidade sugere uma investigação futura para aplicação do método de Araújo e Celes (1). Para o lançamento da malha inicial, pode-se considerar particionar o domínio em macros regiões com alinhamentos diferentes.

O Modelo 5 foi retirado do trabalho de Pochet et al. (16) e também contém restrições prescritas em seu interior. Na Figura 4.23 vemos a malha de quadriláteros do Modelo 5 e suas restrições em vermelho. O campo da magnitude dos vetores de representação da direcionalidade está ilustrado na Figura 4.24. A métrica de qualidade está ilustrada pela Figura 4.24 e em seguida pelo gráfico de barras simples (Figura 4.27). Pelo gráfico de barras, vemos que o intervalo com maior somatório é o de maiores ângulos, isto é, a métrica reporta uma malha de baixa qualidade em relação ao alinhamento. De fato, este domínio é muito desfavorável à obtenção de malhas alinhadas. O campo de direcionalidade do domínio apresenta diversas rotações. O lançamento de uma malha estruturada neste caso exigiria o particionamento do domínio em 


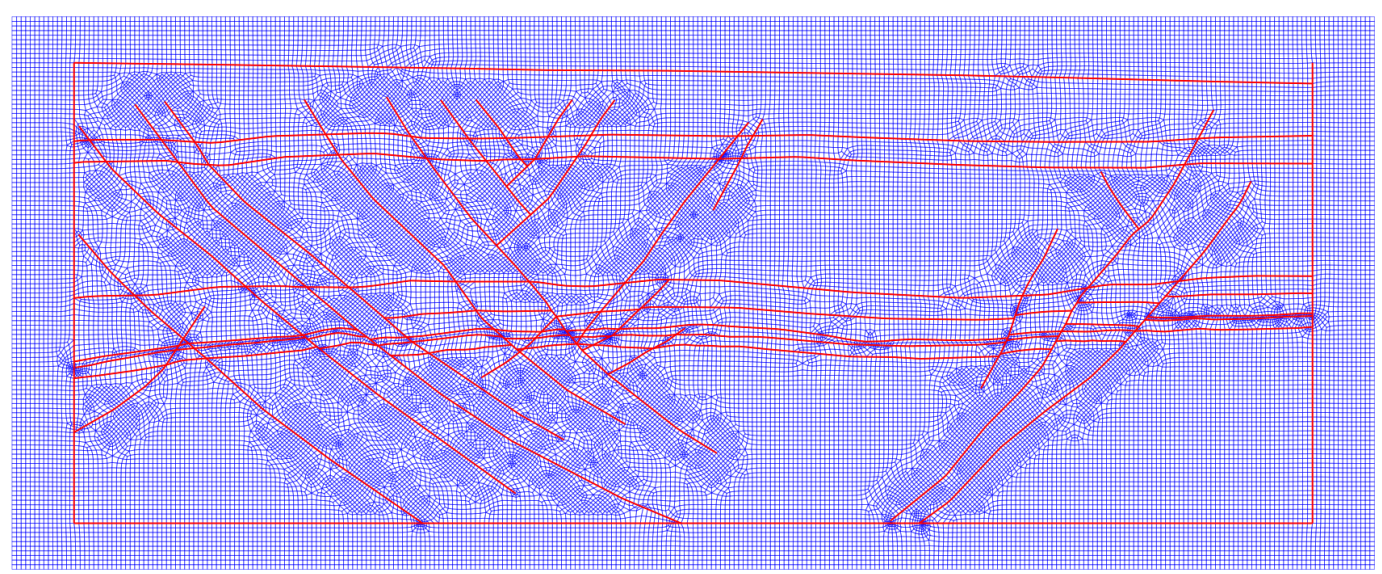

Figura 4.17: Modelo 4 com suas restrições em vermelho.

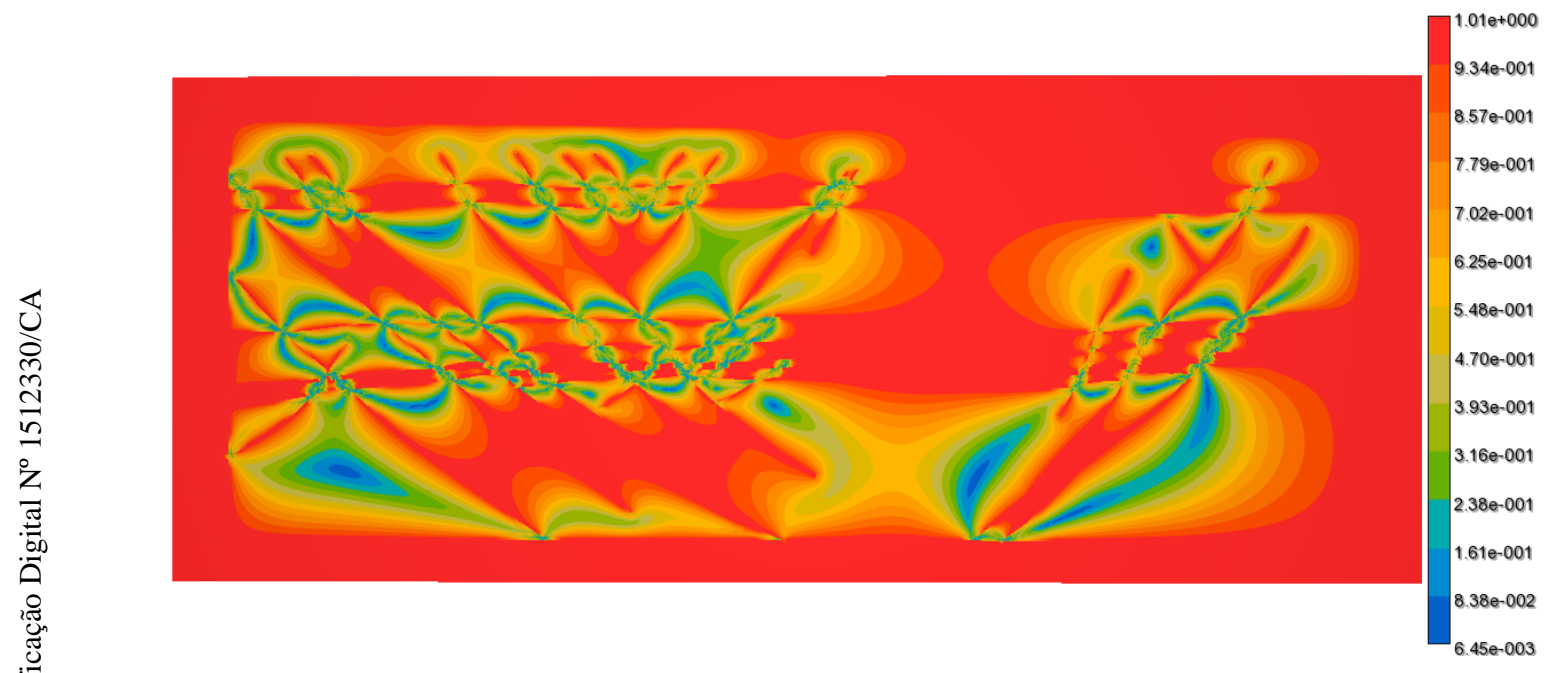

Figura 4.18: Magnitude do campo do vetor de representação da direcionalidade do Modelo 4.

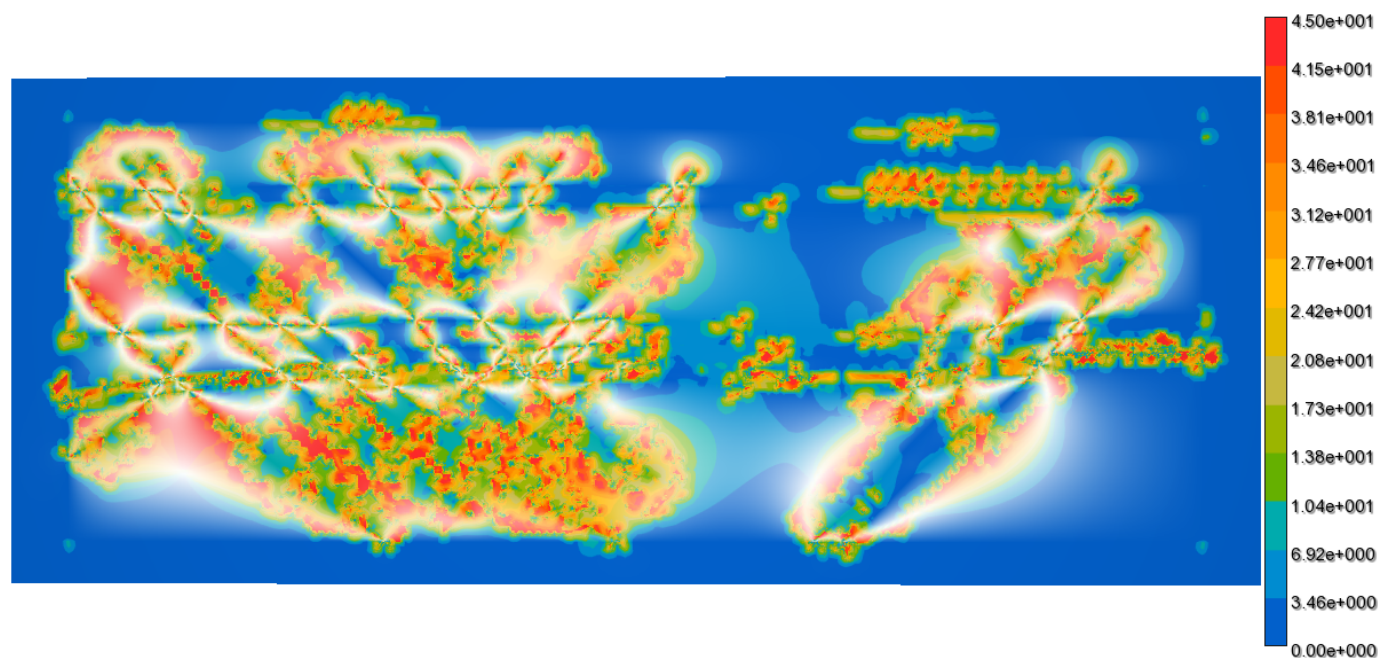

Figura 4.19: Métrica de qualidade de alinhamento para o Modelo 4. 


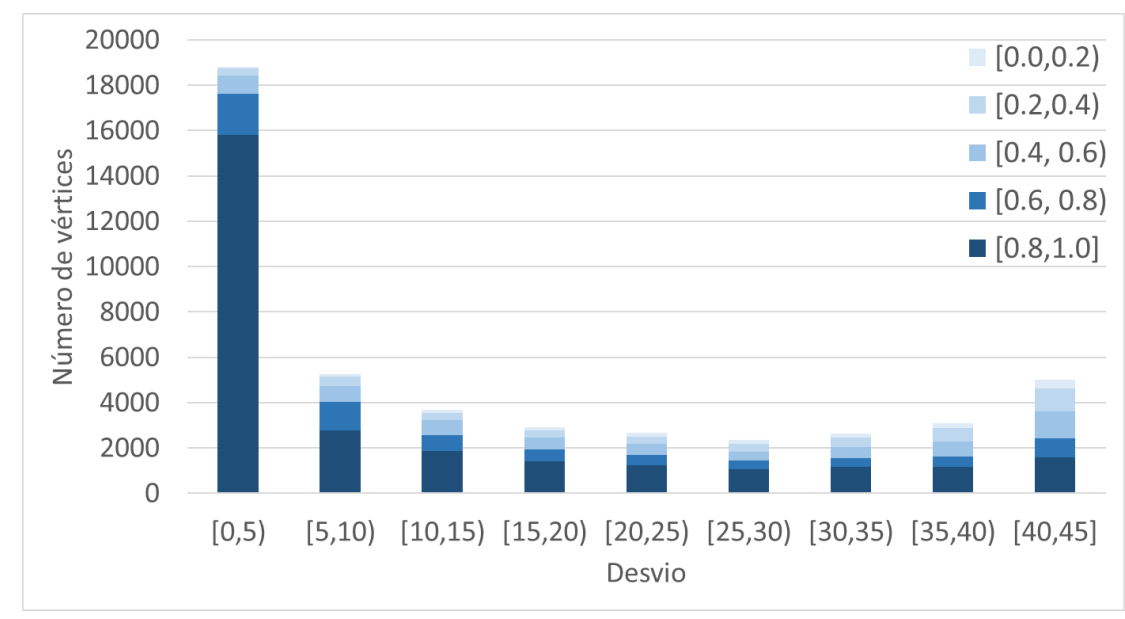

Figura 4.20: Gráfico do desvio quantizado em intervalos de $\alpha$.

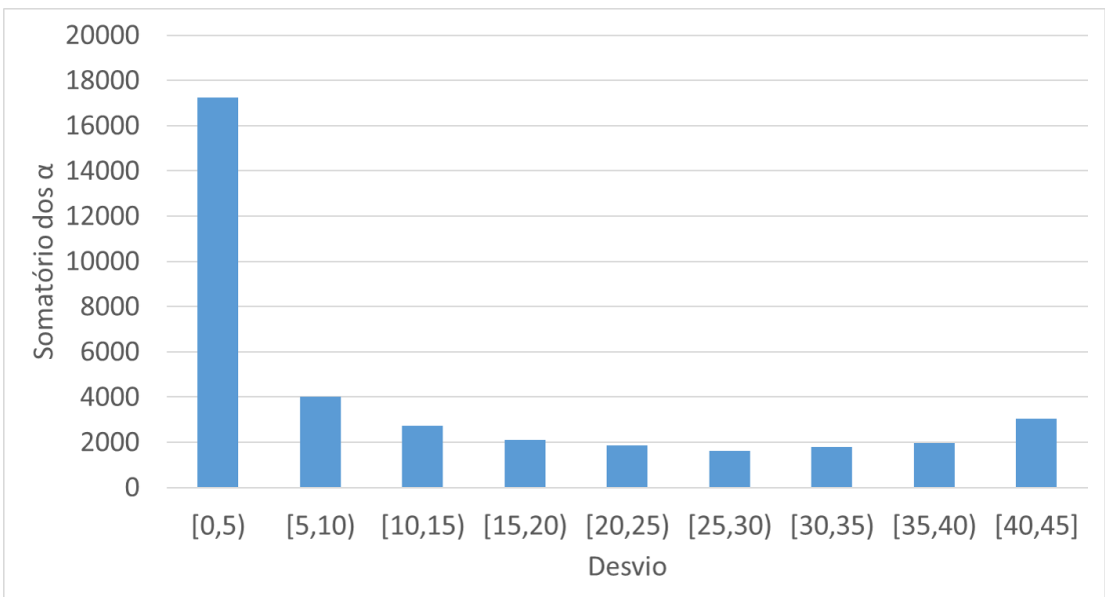

Figura 4.21: Gráfico de barras condensado.

diferentes regiões menores. Além da complexidade do campo de direcionalidade, o método apresentado por Pochet et al. (16) gera a malha baseado numa decomposição do domínio em quadtree, o que favorece o alinhamento com os eixos cartesianos. Além disso, nesse exemplo em particular, optou-se por gerar uma malha com alta variação de discretização. As restrições externas são pouco discretizadas. Os elementos de transição, usados para adaptar a mudança de tamanho dos elementos, apresentam baixa qualidade de alinhamento.

Novamente, métricas de qualidade locais não capturam problemas de alinhamento. Pochet et al. (16) usaram a métrica do Fator de Distorção, apresentada no Capítulo 2, para analisar a qualidade da malha. Essa métrica apresenta bons resultados para esse modelo, pois ela é uma métrica local (analisa o quadrilátero isoladamente) em comparação à nossa que analisa o domínio todo pois usamos a informação do campo de direcionalidade. Por isso as duas métricas deram resultados discrepantes. 


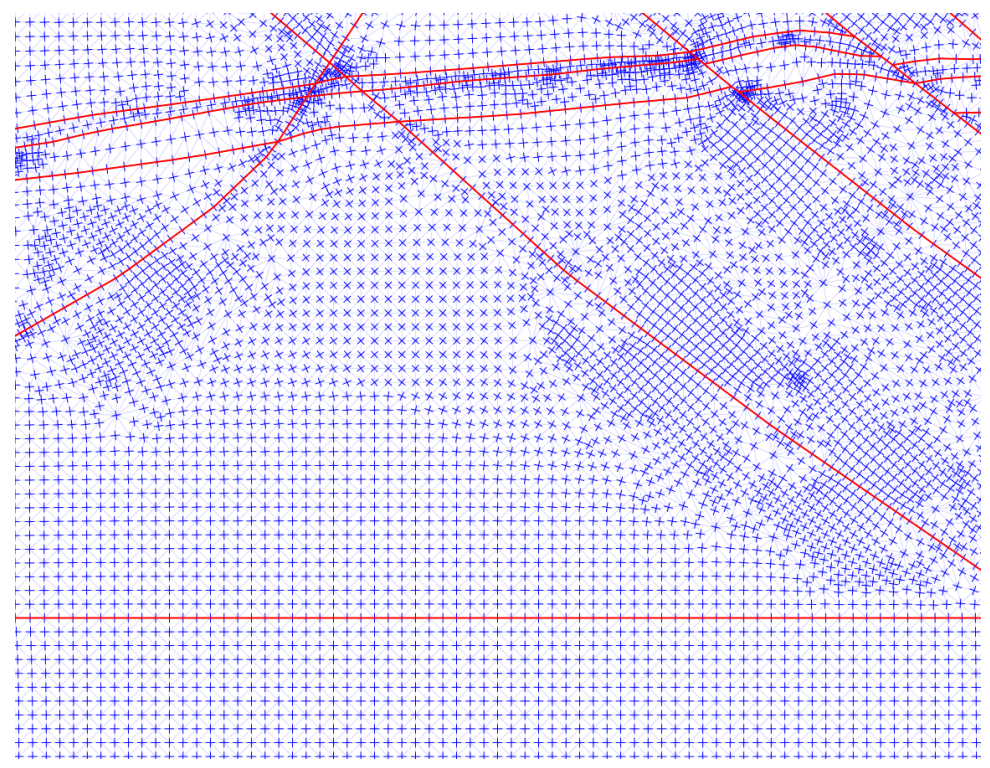

(a) Em azul, a direcionalidade e em vermelho as restrições.

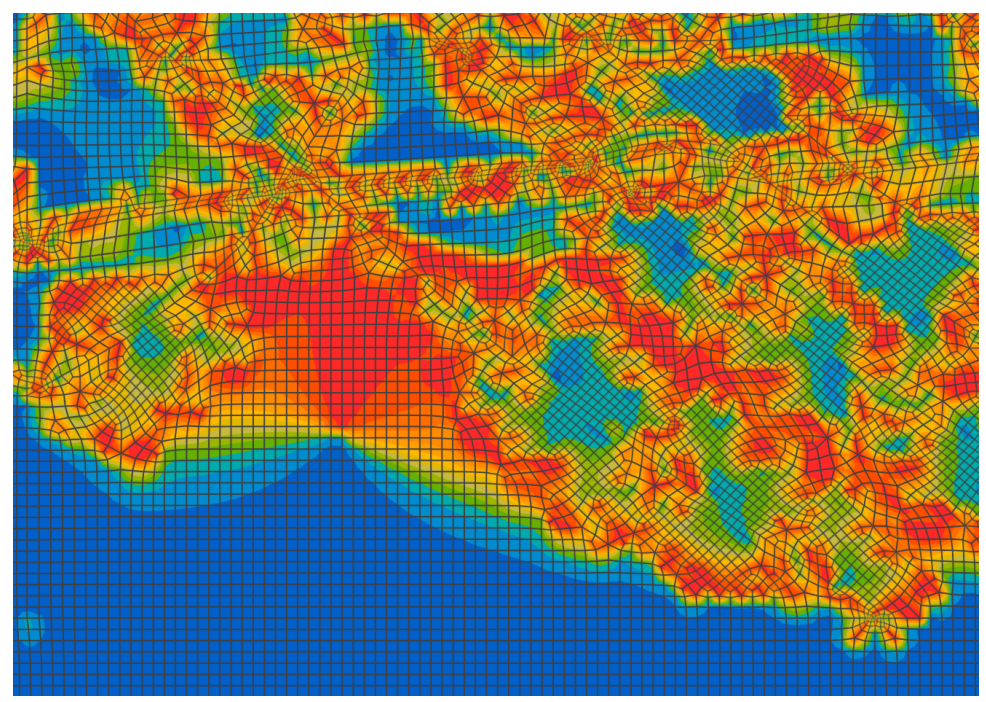

(b) A região em vermelho é a região que contém o maior ângulo $\left(45^{\circ}\right)$ e em azul, o menor ângulo $\left(0^{\circ}\right)$.

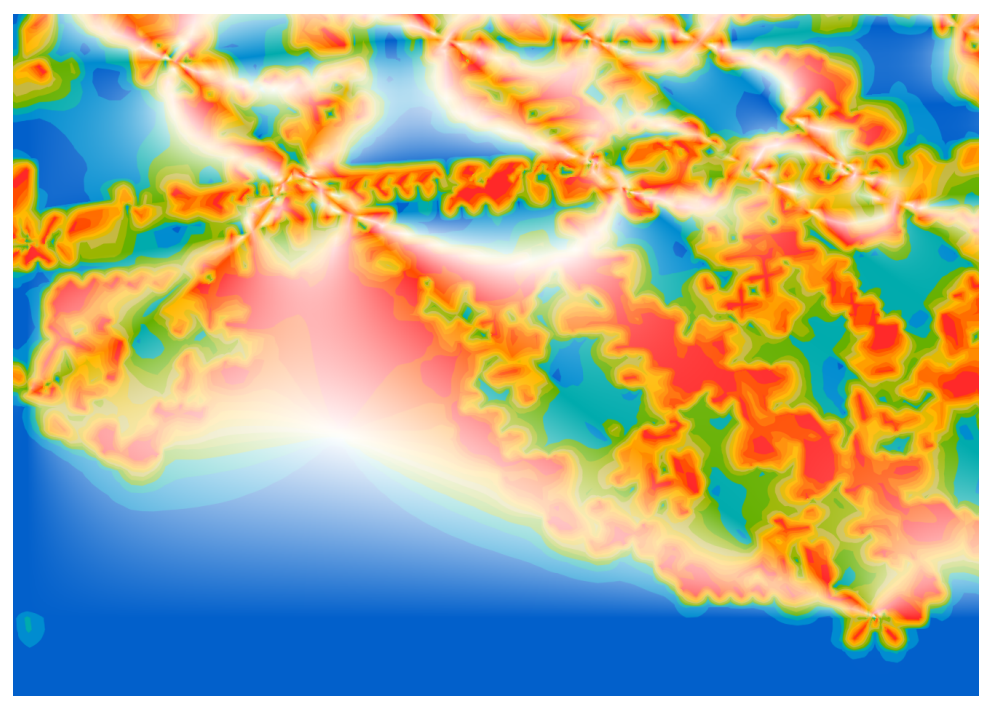

(c) Qualidade de alinhamento

Figura 4.22: Área destacada do Modelo 4 para mostrar o desalinhamento. 


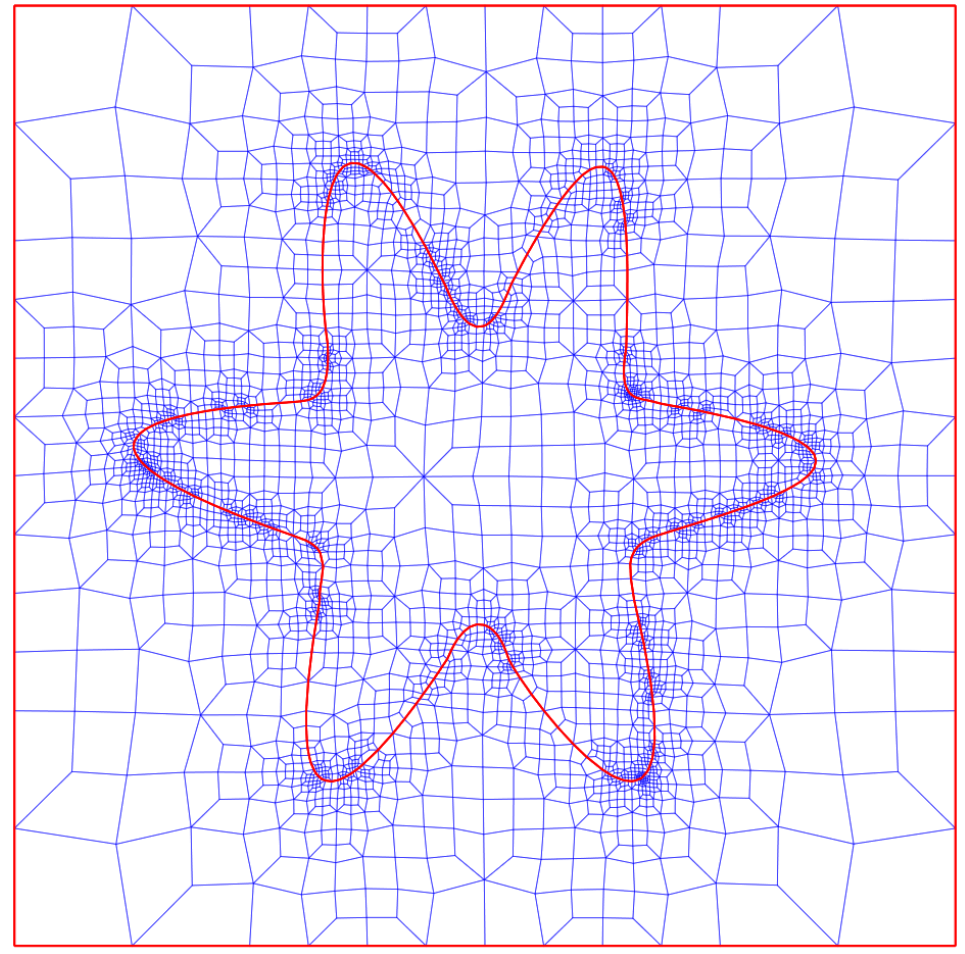

Figura 4.23: Modelo 5 com suas restrições em vermelho.

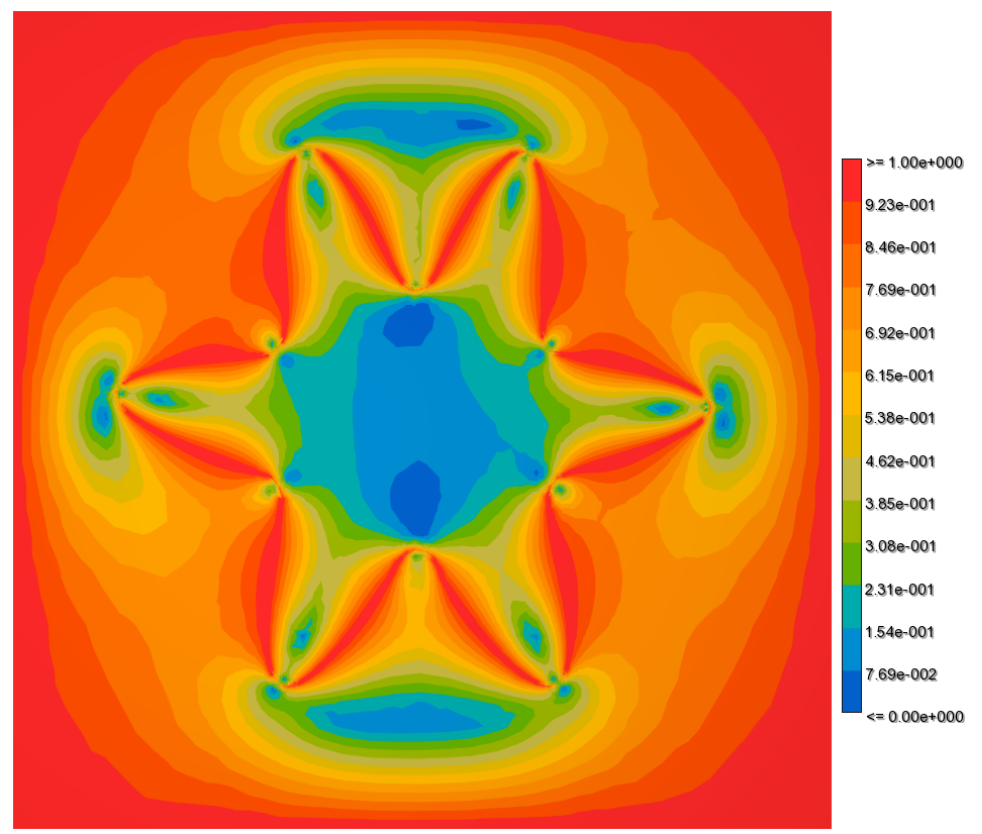

Figura 4.24: Magnitude do campo do vetor de representação da direcionalidade do Modelo 5. 


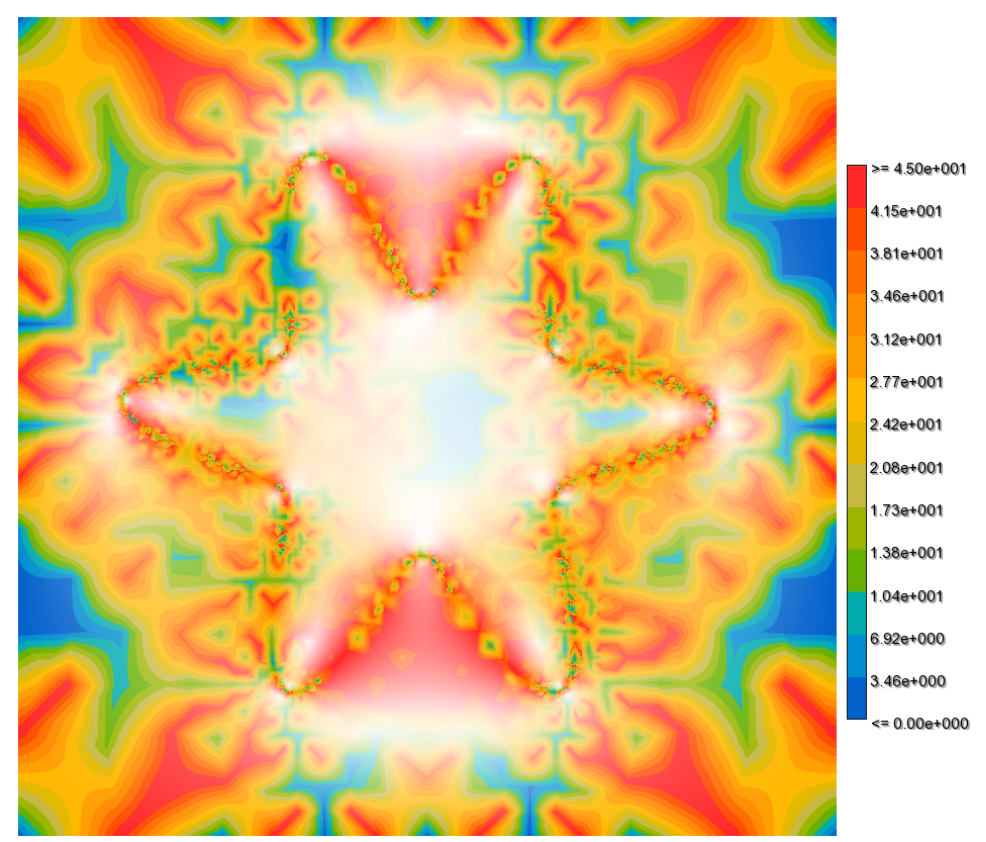

Figura 4.25: Métrica de qualidade de alinhamento para o Modelo 5.

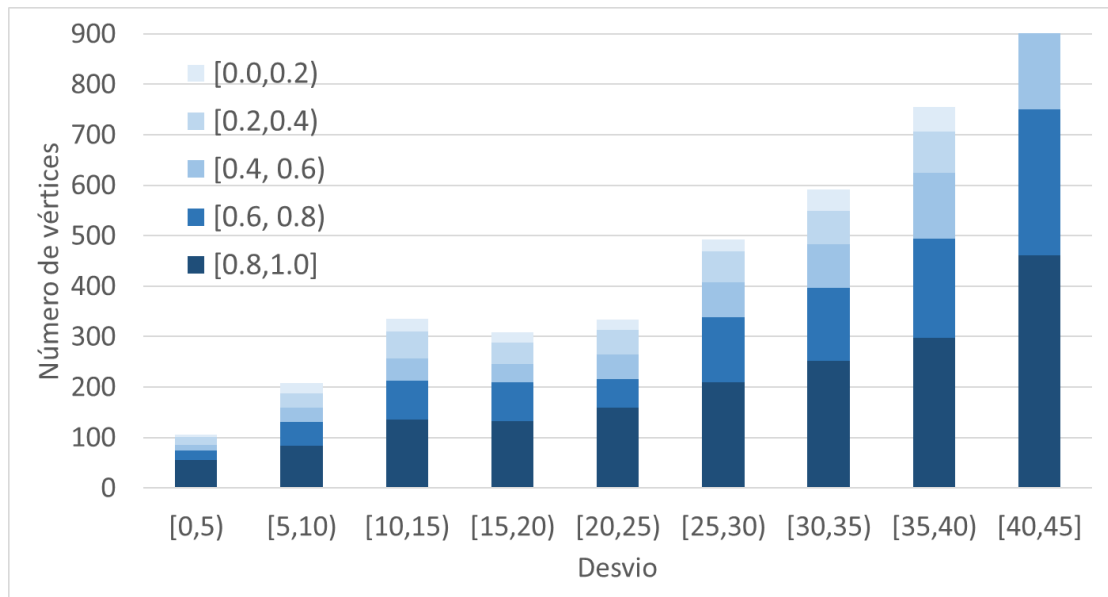

Figura 4.26: Gráfico do desvio quantizado em intervalos de $\alpha$.

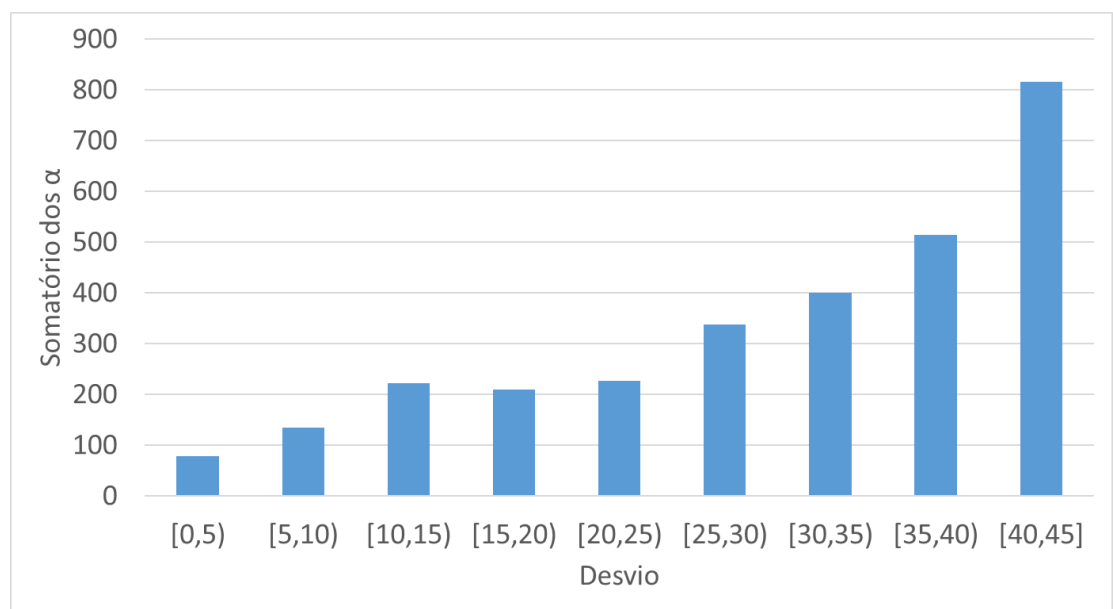

Figura 4.27: Gráfico de barras condensado. 


\section{5}

\section{Conclusão}

Nesta dissertação, foi utilizado um método proposto por Kowalski et al. (9). Este é um método para geração de malhas de quadriláteros a partir da subdivisão do domínio em regiões quadrilaterais e do conceito de direcionalidade. Durante a implementação do método, surgiram algumas discussões que motivaram modificações. O nosso trabalho se preocupou em trabalhar com regiões com restrições e como tratar essas regiões na partição do domínio, respeitando o alinhamento com a direcionalidade. Os resultados mostram domínios subdivididos em regiões quadrilaterais.

Usando esse conceito de alinhamento, observamos que os trabalhos existentes na literatura não analisam o alinhamento como métrica de qualidade. Com essa motivação, criamos uma métrica de qualidade de alinhamento de malhas quadrilaterais. Essa métrica utiliza o conceito de direcionalidade para calcular o desvio angular de cada vértice e utiliza o conceito de magnitude do vetor de representação da direcionalidade em cada vértice como o critério de confiabilidade do desvio. Os resultados mostram que malhas podem ter uma boa qualidade local, mas uma qualidade de alinhamento global ruim. A nossa métrica mostra isso de forma direta.

Mostramos que é possível usar as extremidades das restrições interiores como singularidades geométricas e, a partir delas, lançar mais separatrizes para subdividir o domínio. Como trabalhos futuros queremos explorar o uso de campos de direcionalidade para a decomposição de domínios complexos de modelos geológicos, em um número reduzido de partições, para a geração de malhas iniciais, as quais são posteriormente adaptadas para acomodar as restrições, como no trabalho de Araújo e Celes (1). Também podemos investigar o particionamento do domínio para aplicação do método proposto por Pochet el al. (16), usando uma estrutura de quadtree em cada região particionada. Por fim, parece promissor explorar mapeamentos diretos com restrição. 


\section{Referências bibliográficas}

[1] ARAÚJO, C.; CELES, W.. Quadrilateral mesh generation with deferred constraint insertion. Procedia Engineering, 82:88-100, 2014.

[2] BLACKER, T. D.; BOHNHOFF, W. J. ; EDWARDS, T. L.. CUBIT mesh generation environment. Metrics for Quadrilateral Elements. https://cubit.sandia.gov/public/13.2/help_manual/WebHelp/ mesh_generation/mesh_quality_assessment/quadrilateral_ metrics.htm. Acessado: 20-09-2017.

[3] BLACKER, T. D.; STEPHENSON, M. B.. Paving: A new approach to automated quadrilateral mesh generation. International Journal for Numerical Methods in Engineering, 32(4):811-847, 1991.

[4] BOMMES, D.; LÉVY, B.; PIETRONI, N.; SILVA, C.; TARINI, M. ; ZORIN, D.. State of the art in quad meshing. 2012.

[5] BOMMES, D.; ZIMMER, H. ; KOBBELT, L.. Mixed-integer quadrangulation. ACM Trans. Graph., 28(3):77:1-77:10, July 2009.

[6] CELES, W.; PAULINO, G. H. ; ESPINHA, R.. A compact adjacencybased topological data structure for finite element mesh representation. International Journal for Numerical Methods in Engineering, 64(11):1529-1556, 2005.

[7] CONTE, S. D.; BOOR, C. W. D.. Elementary Numerical Analysis: An Algorithmic Approach. McGraw-Hill Higher Education, 3rd edition, 1980.

[8] DE OLIVEIRA MIRANDA, A. C.; MARTHA, L. F.. Hierarchical templatebased quadrilateral mesh generation. Engineering with Computers, 33(4):701-715, Oct 2017.

[9] KOWALSKI, N.; LEDOUX, F. ; FREY, P.. A pde based approach to multidomain partitioning and quadrilateral meshing. In: PROCEEDINGS OF THE 21ST INTERNATIONAL MESHING ROUNDTABLE, p. 137-154. Springer, 2013. 
[10] KOWALSKI, N.; LEDOUX, F. ; FREY, P.. Automatic domain partitioning for quadrilateral meshing with line constraints. Engineering with Computers, 31(3):405-421, 2015.

[11] KOWALSKI, N.; LEDOUX, F. ; FREY, P.. Smoothness driven frame field generation for hexahedral meshing. Computer-Aided Design, 72:65-77, 2016.

[12] LEE, K.-Y.; KIM, I.-I.; CHO, D.-Y. ; KIM, T.-W.. An algorithm for automatic $2 \mathrm{~d}$ quadrilateral mesh generation with line constraints. Computer-aided design, 35(12):1055-1068, 2003.

[13] MARSCHNER, S.; SHIRLEY, P.. Fundamentals of computer graphics. CRC Press, 2015.

[14] PALACIOS, J.; ZHANG, E.. Rotational symmetry field design on surfaces. ACM Transactions on Graphics (TOG), 26(3):55, 2007.

[15] PARK, C.; NOH, J.-S.; JANG, I.-S. ; KANG, J. M.. A new automated scheme of quadrilateral mesh generation for randomly distributed line constraints. Computer-Aided Design, 39(4):258-267, 2007.

[16] POCHET, A.; CELES, W.; LOPES, H. ; GATTASS, M.. A new quadtreebased approach for automatic quadrilateral mesh generation. Engineering with Computers, 33(2):275-292, 2017.

[17] RAY, N.; VALLET, B.; LI, W. C. ; LÉVY, B.. N-symmetry direction field design. ACM Trans. Graph., 27(2):10:1-10:13, May 2008.

[18] SHIMADA, K.; LIAO, J.-H.; ITOH, T. ; OTHERS. Quadrilateral meshing with directionality control through the packing of square cells. In: IMR, p. 61-75, 1998.

[19] TAM, T.; ARMSTRONG, C.. 2d finite element mesh generation by medial axis subdivision. Advances in Engineering Software and Workstations, 13(5):313 - 324, 1991.

[20] TARINI, M.; PUPPO, E.; PANOZZO, D.; PIETRONI, N. ; CIGNONI, P.. Simple quad domains for field aligned mesh parametrization. ACM Transactions on Graphics (TOG), 30(6):142, 2011.

[21] TECGRAF/PUC-RIO. gHEM. http://www.tecgraf .puc-rio.br/pt/ software/sw-tectos.html. Acessado: 20-09-2017. 
[22] TECGRAF/PUC-RIO. Sigma 2D e 3D (MTOOL e Pos-3D). http: //www. tecgraf .puc-rio.br/pt/software/sw-sigma.html. Acessado: 21-09-2017.

[23] TRICOCHE, X.; SCHEUERMANN, G. ; HAGEN, H.. Continuous topology simplification of planar vector fields. In: PROCEEDINGS OF THE CONFERENCE ON VISUALIZATION '01, VIS '01, p. 159-166, Washington, DC, USA, 2001. IEEE Computer Society.

[24] WANG, B.-L.; MAI, Y.-W.. Transient one-dimensional heat conduction problems solved by finite element. International Journal of Mechanical Sciences, 47(2):303-317, 2005.

[25] WHITE, D. R.; KINNEY, P.. Redesign of the paving algorithm: Robustness enhancements through element by element meshing. In: 6TH INTERNATIONAL MESHING ROUNDTABLE, volumen 10, p. 830, 1997. 